\title{
Sustainability in Heritage Wood Conservation: Challenges and Directions for Future Research
}

\author{
Zarah Walsh-Korb 1,2
}

1 Department of Chemistry, University of Basel, 4058 Basel, Switzerland; zarah.korb@unibas.ch; Tel.: +41-61-207-5960

2 Department of Biosystems Science and Engineering, ETH Zurich, 4058 Basel, Switzerland

check for updates

Citation: Walsh-Korb, Z. Sustainability in Heritage Wood Conservation: Challenges and Directions for Future Research. Forests 2022, 13, 18. https:/ / doi.org/10.3390/f13010018

Academic Editors: Magdalena Broda and Callum A. S. Hill

Received: 1 December 2021

Accepted: 21 December 2021

Published: 23 December 2021

Publisher's Note: MDPI stays neutral with regard to jurisdictional claims in published maps and institutional affiliations.

Copyright: (c) 2021 by the author. Licensee MDPI, Basel, Switzerland. This article is an open access article distributed under the terms and conditions of the Creative Commons Attribution (CC BY) license (https:// creativecommons.org/licenses/by/ $4.0 /)$.

\begin{abstract}
Conserving the world's cultural and natural heritage is considered a key contributor to achieving the targets set out in the United Nation's Sustainable Development Goals, yet how much attention do we pay to the methods we use to conserve and protect this heritage? With a specific focus on wooden objects of cultural heritage, this review discusses the current state-of-the-art in heritage conservation in terms of sustainability, sustainable alternatives to currently used consolidants, and new research directions that could lead to more sustainable consolidants in the future. Within each stage a thorough discussion of the synthesis mechanisms and/or extraction protocols, particularly for bio-based resources is provided, evaluating resource usage and environmental impact. This is intended to give the reader a better understanding of the overall sustainability of each different approach and better evaluate consolidant choices for a more sustainable approach. The challenges facing the development of sustainable consolidants and recent research that is likely to lead to highly sustainable new consolidant strategies in the future are also discussed. This review aims to contribute to the ongoing discussion of sustainable conservation and highlight the role that consolidants play in truly sustainable heritage conservation.
\end{abstract}

Keywords: heritage wood; conservation; sustainability; bio-based polymers; consolidants

\section{Introduction}

Wood is an anisotropic, hierarchical material with a three-dimensional fibrous structure composed primarily of cellulose and hemicelluloses, that self-assemble on the nanoscale and are bound into the macroscale structure of wood tissue by lignin [1-3]. It is a widely available natural resource that has been used for centuries to create everything from kitchen utensils to dwellings and transportation. As such, wooden artefacts are common objects in the historical record [3].

Depending on where a wooden artefact is found it will have been subjected to a variety of biotic and abiotic stresses that exert significant influence on the extent and the speed of its degradation [4-7]. All wooden objects will have been exposed to a greater or lesser extent to abiotic factors such as temperature, light, and moisture. Degradation as a function of normal abiotic stress is generally rather slow and such objects can often be displayed or stored with minimal or no active consolidation, although storage in a controlled environment would be recommended to maintain the slow rate of natural degradation [8,9]. At extremes of abiotic stress, particularly moisture, accelerated biotic degradation is often encountered, primarily in the form of wood-decaying fungi and bacteria, although insects and marine borers are also common in certain environments [4]. The action of these organisms can significantly speed up the degradation of wood, through the decomposition of the cellulosic or lignin components, which is highly dependent on the organism. Their action requires mitigation through the use of biocides and/or consolidant treatments to hinder biological activity and maintain the mechanical stability of the artefact. In the majority of cases, the consolidants employed are polymers derived from petrochemical refining. 
The Sustainable Development Goals, which form part of the United Nations Agenda for 2030, list strengthening "efforts to protect and safeguard the worlds' cultural and natural heritage" as a key target to achieving safe, resilient, inclusive and sustainable cities and human settlements (Goal 11) [10]. However, the methods we use to achieve this conservation are not always sustainable themselves. While some natural resins and inorganic minerals are used in wood conservation, many consolidants are petroleum-based. Poly(ethylene glycol) (PEG) [11-15], epoxy-based glues [16], melamine-formaldehyde (MF) resins [17-19] and acrylate or methacrylate copolymers $[20,21]$ are all regularly employed in conservation of wooden objects of cultural importance. As these treatments are by-products of the petroleum industry, their production is inherently unsustainable [22]. The result is that we regularly use highly unsustainable materials, often in large quantities, to 'sustain' our cultural heritage.

Currently, only $5-20 \%$ of extracted crude oil is refined into chemicals at most refineries [22], with the remainder being used for energy and transportation. This includes the raw materials to produce PEG, MF resins, epoxy, alkoxide (alkoxysilane), methacrylate and acrylate consolidants. With the signing of the Paris Agreement in 2015 [23-28], many countries and institutions pledged to phase out the use of fossil fuels by 2050. What does this mean for the polymers used regularly in the conservation laboratory? One would think that phasing out fossil fuels in the energy sector would reduce the attraction of oil refining and force a switch to more renewable chemical consolidants. Unfortunately, this may not be the case [29]. The reduction in demand for oil for energy and transport means refineries and oil companies are changing their business models and refocusing on petrochemical production [30]. In the coming two decades, petrochemicals will likely make up almost $80 \%$ of the products of oil refineries [22]. This significant increase in the availability of non-renewable raw materials for polymers will drive the cost of virgin polymers and plastics down, to the point that it may be more cost-effective to continue using non-renewable consolidants than recyclable or bio-based alternatives [31]. Knowing that cultural institutions often run on very lean budgets [32], the barrier to creating more sustainable conservation methods will increase significantly.

Despite this significant economic driver towards less sustainable conservation practices, the continuation of unsustainable practices across all fields will eventually lead to significant and irreversible damage to our environment with extraordinary economic costs [33], that no amount of cheap petroleum-based products will stem. Thus, there are two strategies we need to enact to ensure a more sustainable conservation practice and do our part to reduce the impact of petroleum-based products on the environment. In the short term, we need to choose sustainable alternatives to current consolidants. This is not a perfect solution, as bio-based alternatives to petroleum-based chemicals are often just as environmentally unfriendly and difficult to dispose of as their fossil-based counterparts [34]. However, their bio-based sourcing does reduce the environmental impact of their production. Unfortunately, commercially available, sustainably sourced alternatives do not exist for all commonly used consolidants. Thus, the longer-term strategy is to explore new bio-inspired alternatives to our current consolidants. This not only requires advances in materials science research but also a mindset shift across all levels of the museum and conservation hierarchy. We must move away from the unsustainable stateof-the-art and embrace sustainable consolidants as a key aspect of the future conservation toolkit, alongside environmentally friendly conservation practices (i.e., use and disposal of gloves and other consumables) and replacement of lighting and ventilation systems with low energy alternatives [35]. Over the following sections, the current state-of-the-art in conservation treatments will be discussed with a specific focus on sustainable alternatives to petroleum-based consolidants and new directions in sustainable consolidant design.

\section{Consolidants for Wooden Heritage Objects: The Current State-of-the-Art}

In the context of wooden objects of cultural importance, there are several commonly used consolidants. These treatments can be broken down into three principal categories: 
synthetic, inorganic and bio-based. In the following sections, an overview of the various aspects of consolidant production is given to heighten awareness of the sustainability and environmental impact of the processes involved in their production. This is not a thorough life cycle analysis of each material, which would be outside the scope of this review. However, if we are to increase sustainability in wood conservation, we must be aware of the processes involved in the production of consolidants, to understand whether treatments marked as sustainable alternatives are really an improvement on the state-of-the-art.

Inorganic treatments are the least commonly used in wood conservation, being more heavily exploited in stone and masonry conservation. Those that are used can be divided into two categories-inorganic nanoparticles (INPs) and inorganic polymers. INPs are primarily mined rather than synthesised, thus, their discussion requires a detailed look at the sustainability and practices of the mining industry, which is also too broad a discussion for this review. As such, the discussion of inorganic consolidants will be limited to inorganic polymers that include a petroleum-based component, such as alkoxymethylsilanes. These inorganic polymers are included under the synthetic consolidant section.

\subsection{Bio-Based Consolidants}

Interestingly, the origins of wood consolidation are rather sustainable, insofar as the consolidants have been obtained from renewable resources. Natural resins, oils, and waxes have long been used to preserve and treat wood [36-39]. Waxes (e.g., beeswax obtained from the hives of honey bees (Apis mellifera Linneaus, 1758)), resins (e.g., colophony (rosin) obtained from the sap of various pine (Pinus spp.) species) and oils (specifically linseed (from Linum ussitatissimum L.) and Tung (from Vernicia fordii (Hemsl.) Airy Shaw), have been used to fill cracks, stabilise mechanical properties and enhance the aesthetic qualities of wooden objects for centuries [3]. Their hydrophobicity is also used to improve the waterrepellency of wood, reducing susceptibility to bacterial degradation. With the advent of industrial-scale extraction of sucrose for the food industry, sugar conservation also became popular, due to the increased mechanical stability of sugar-conserved wood and its realistic wood-like appearance. Non-reducing sugars and sugar alcohols have also been introduced to the conservation toolkit over the years.

A common misconception is that bio-based consolidants, being obtained from nature, are more sustainable than petroleum-based chemicals. While this is generally true with respect to the renewability of the resource, the methods of cultivation and the processes used to extract and refine these bio-based consolidants into a useable form are often highly damaging to the environment and this must also be taken into consideration. These aspects are discussed in more detail in the following sections.

\subsubsection{Oils}

Within this class, oils from linseed and tung are the most commonly used. Their relatively low viscosity means that they are used both to enhance the surface aesthetics of the wood by creating a varnished look, as well as penetrate deeper into wooden objects, enhancing the hydrophobicity within their structure [3].

Linseed oil is obtained from flax (L. ussitatissimum), an annual crop that exists in two forms, fibre flax and linseed [40]. The former produces high-quality fibres used in the textile industry as linen, while the latter produces lower quality fibres but large quantities of oilseed, from which linseed oil is extracted. With its popularity in the food, textile and automotive industries, it is widely cultivated across North America and large parts of Europe, in areas with cooler temperatures and high rainfall that mean little demand for additional water to maintain crop growth [40]. Otherwise, the cultivation of flax is highly resourceintensive and damaging to the environment. Both flax cultivars have poorly developed root systems and low nutrient uptake, with a low resistance to pests, weeds and disease. Thus, they rely heavily on the use of agrochemicals, derived from petroleum, to sustain high outputs matching demand. High use of agrochemicals combined with soil runoff due to the poor structure of flax roots contributes to eutrophication and degradation of soil quality. 
Crop rotations with potatoes and beets, known for their excellent soil structuring and cleaning properties, as well as employing organic manure and natural pest control systems can help reduce the environmental impact of flax leading to more sustainable cultivation and a lower environmental impact [41], however, this is not yet the state-of-the-art. In terms of oil extraction, while cold mechanical pressing is used to obtain food-grade linseed oil [42], warm pressing or solvent extraction is used to retrieve linseed oil for conservation purposes [43]. These techniques lead to greater oil expression but require more input energy or the use of toxic (petroleum-based) solvents, which then require incineration further impacting the environmental footprint of linseed oil. More recently, supercritical and green solvent extraction methods have been explored to extract comparable quantities of oil from oilseeds as their less environmentally friendly counterparts [43,44]. This will hopefully lead to a further reduction of the environmental impact of linseed oil production on the environment. On a positive note, despite their lower fibre quality, fibres from linseed are used as reinforcements in the automotive industry, valorising the waste from oil production and improving the sustainability of crop cultivation, with less material going to waste [40]. A disadvantage of linseed oil as a consolidant is its slow-drying nature, which can lead to softening of the wood during the drying period. This affects the stability of the artefact and has led to much research on improving the drying properties of linseed oil through chemical modifications of the triglyceride structure. An example of this is the epoxidation of linseed oil to create linseed oil-based epoxy resins [45,46], which are discussed in more detail in Section 3.2. While these modifications have significantly enhanced their application in wood conservation, they have impacted the sustainability of linseed oil by reducing the resource efficiency of the consolidant production. Interestingly, while these modifications reduce the sustainability of linseed oil as a consolidant, epoxidised linseed oil is seen as a major improvement to the sustainability of epoxy consolidants, removing a significant amount of the non-renewable component of these adhesives.

Tung oil is obtained from the fruit of the tung tree $(V$. fordii) native to southern China. Tung oil has been used for centuries in China as a wood consolidant and for waterproofing of wooden ships and boats [47]. Its fast-drying nature is an enhancement over the slow-drying properties of linseed oil [48]. This can, however, lead to issues with heterogeneous film formation and incomplete protection of heritage wood, when used alone as a wood consolidant. Thus, combination with thinners is generally recommended to enhance the overall protection of the wood. Interestingly, this fast-drying property led to increased demand for tung oil in the paint industry in the early part of the 20th century to create fast-drying paints with a lower environmental footprint $[49,50]$. Thus, tung trees were cultivated on an industrial scale to match this new demand. Unlike, the industrial-scale cultivation of linseed, tung trees created a much lower environmental impact. Firstly, tung is a perennial crop, and while it cannot be said that perennials are always more environmentally benign than annual crops due to various dependencies on agrochemicals, the continual growth cycle in comparison to the fragile seedling stage that must be revisited each year does generally reduce overall environmental burden [51]. Perennial crops, combined with low reliance on agrochemicals, are seen as an integral component of sustainable agriculture [52]. Moreover, tung trees have a highly efficient photosynthesis mechanism that leads to initial fruiting, and thus initial oil production, within three years, one of the fastest of all commercial oil crops [53]. The hardy nature of the tung tree reduces the need for extensive agrochemicals, as such, the overall cultivation of tung oil is relatively environmentally friendly. With respect to oil extraction, the same methods are employed with equal environmental concerns as for other oilseeds. However, the advent of green extraction processes, as detailed previously, will likely contribute to further improvement of the overall environmental impact of tung oil, making it one of the most sustainable wood consolidants currently available. 


\subsubsection{Waxes and Resins}

In contrast to linseed and tung oil, colophony, and beeswax, due to their high viscosity, have generally been confined to surface treatment [37]. Their major advantages are the ability to fill gaps in the wood surface and bind fragile fragments of the surface, preventing loss and increasing mechanical stability. Their high viscosity, however, means that they often must be heated to penetrate the surface of the wood. Depending on the state of degradation of the wood, the high temperature of the melted treatment can cause darkening of the wood or weakening of the structure if the glass transition temperature of the remaining wood components is exceeded [3].

Looking first at beeswax, produced from the wax secreting glands of the honeybee (A. mellifera) $[54,55]$. The primary function of the wax is to template the formation of the honeycomb that will eventually breed larvae and store pollen and the resulting honey [56]. On a small scale, beeswax is extracted by first warming $\left(35-40{ }^{\circ} \mathrm{C}\right)$ and liquefying the honey. As beeswax melts between $60-65^{\circ} \mathrm{C}$, the wax remains solid and can be filtered from the surface of the liquid honey and then cleaned. This can be melted to form wax cakes that are used for a variety of applications. Bees are not physically harmed by the extraction of the wax from the hive and can continue to thrive after extraction by 'recombing' the hive, thus, it is generally thought that beeswax is a sustainable natural product. However, very little wax is extracted from small apiaries, thus, beeswax is often obtained from industrial beekeeping. The link between industrial beekeeping and monocultures, specifically almond and avocado crops, with respect to the high use of agrochemicals and their environmental impact raises questions about the sustainability of beeswax [57]. The environmental impact of monocultures means we must reconsider the environmental sustainability of beeswax [58-60]. This wax is more commonly extracted using solvent heavy extraction processes involving petroleum-derived dimethylformamide and hexane, to ensure removal of pesticides from the final wax product [61]. Moreover, industrial hives are often sacrificed after the harvest to reduce the cost of sustaining colonies over winter [57], thus, increasing the negative environmental and, for many, the ethical impact of the use of beeswax.

Resin tapping, the process by which colophony is obtained from many species of pine (Pinus spp.), is a simple process in which a section of bark is removed, and an incision is made in the outer layers of the tree to encourage resin secretion [62]. A vessel is attached to the tree to collect the expressed resin, a process which is often repeated exhaustively until the tree is felled. Resin tapping is often an integral part of sustainable forestry management for a number of reasons, including the increase in production of resin within the tree as a function of tapping, making it a renewable bio-resource [63]. Moreover, resin tapping increases the profitability of pine stands, creating a sustainable source of income in economically depressed and rural areas [64]. Resin tapping activities also promote increased forest management, often resulting in a lower incidence of forest fires. Many studies have also examined the impact of pine tapping on the wood quality and sensitivity of the trees to climatic and environmental stress [65-68]. While there is often mechanical damage to the wood at the site of tapping, overall, the impact on the quality of the felled wood has been negligible. In fact, some studies have shown that tapped wood is more elastically deformable and less rigid and brittle than untapped wood, contributing to the increased value of the felled wood [69]. Furthermore, it has been observed that tapped trees are no more sensitive to climatic changes and environmental stress than untapped trees, meaning no reduction in stability of forest stands due to resin extraction. Thus, colophony, at least from a sourcing point of view, is an extremely sustainable, environmentally responsible consolidant. Obtaining rosin, and its more valuable counterpart, turpentine, from the tapped resin is a more energy-intensive process known as destructive distillation [70]. Here, the resin is heated to just over $200^{\circ} \mathrm{C}$ to distil off phenols and terpenes and degrade unnecessary biological components of the tar (wood shards, insects, etc.), the remaining gum is the rosin, which is then washed and recrystallised several times using ether and 1\% solutions of $\mathrm{NaOH}$ to give a pure rosin cake. In comparison to its highly sustainable and 
environmentally friendly sourcing, extraction of pure rosin is more energy and resourceintensive. However, advances in green solvent extraction, already discussed with respect to linseed oil extraction could certainly be employed to reduce the environmental impact of the extraction process, increasing the overall sustainability of the final consolidant.

\subsubsection{Sugars and Sugar Alcohol}

Sugars, particularly sucrose obtained from sugarcane (Saccharum spp.) and sugar beet (Beta vulgaris L.), have also long been employed in the conservation of wooden objects [71]. For conservation, objects are immersed in high concentration solutions that penetrate the wood structure. Controlled drying of the artefact leads to the formation of crystals within the structure that stabilise the wood and enhance mechanical stability [71]. While sucrose is widely available at low cost, due to its use in the food industry, care must be taken during impregnation to avoid bacterial infestations of the wood due to the affinity of bacteria for the sugar solutions and during drying to prevent the formation of excessively large crystals that could rupture the wood cells.

Both sugarcane and beet are cultivated extensively for use in the food industry. In 2020, sugar production reached 187 million tonnes and is set to increase by $3 \%$, to 193 million tonnes, by the end of 2021 [72]. Sugar production has not historically been an environmentally friendly crop, with the tendency to grow sugarcane in extensive monocultures that are highly detrimental to biodiversity and soil quality [73,74]. Monocultures generally require extensive use of agrochemicals to ensure resistance to pests, further damaging soil quality. However, since the mid-2000s, efforts have been made by some of the world's largest sugar producers, particularly in the UK (beet) and Brazil (cane), to improve the environmental impact of both sugar crops. With respect to beet, there is a tendency to grow crops in rotation rather than in monocultures [75] and the advent of green biotechnology has allowed the cultivation of new varieties with greater pest resistance, contributing to a $65 \%$ reduction in the use of agrochemicals from $2.0 \mathrm{~kg} /$ tonne of beet crop in 1975-80 to $0.7 \mathrm{~kg} /$ tonne in 2006 and 2007 [76]. In the UK, this has been reduced even further to total agrochemical usage of 414.5 tonnes in 2018 for a beet production of 6.94 million tonnes, equating to $0.06 \mathrm{~kg}$ /tonne [77], a reduction of 97\% from 1980s levels. In Brazil, where sugarcane is the primary sugar source, the enhancement of biodiversity on sugar plantations has considerably improved the impact of cane cultivation on the environment. Growing specifically selected complementary crops alongside sugarcane attracts a variety of wildlife and insects that are natural predators of sugarcane pests, thus functioning as natural pest control, reducing or eliminating the need for agrochemicals [78]. One of the best examples of this is the sugarcane plantations of the Balbo group, which alone produces $34 \%$ of the worlds exported sugar [79]. Their plantation is now exclusively maintained by organic and sustainable agriculture practices improving the environmental impact of sugar cultivation.

Despite significant advances in the enhancement of the sustainability of sugar crops, extraction of sucrose from cane or beet is an energy-intensive process [80], in which the cane is crushed and milled and beet is sliced and diffused to extract the raw juice. This is then followed by heating, liming and clarification (in a different order depending on the starting material), and finally, filtration in the case of beets, to produce the thin juice that is then evaporated and crystallised to give raw sugar. Further refining is carried out to give the white sugar we recognise as table sugar or sucrose [76]. To offset the energy demands of extraction, many sugar refineries are switching to renewable energy to drive these processes, reducing $\mathrm{CO}_{2}$ emissions in the process. In some cases, this renewable energy is even produced from the by-products of the pulping process, specifically bioethanol and biogas from the fermentation of the beet pulp or sugarcane bagasse, creating a circular system for the extraction of sugar and the valorisation of waste products. Further valorisation of waste products from sugar production includes renewable energy, animal feed, soil enhancers and bio-fertilisers and bioethanol. As such, at many refineries very little of the by-products of the sugar extraction go to waste, creating a more sustainable and circular system with 
reduced environmental impact. One of these waste products, sugarcane bagasse [81], is the starting material for bio-glycerol production and will be discussed in more detail in Section 3. Thus, in terms of sustainable consolidants, sucrose is certainly an increasingly environmentally friendly option.

Some alternatives to sucrose have also been explored, specifically lactitol, a sugar alcohol obtained from lactose, and trehalose, a non-reducing sugar found in prokaryotes. While their chemical and environmental stability is much greater than that of sucrose, particularly with respect to bacterial infestation, the dimensional stability of artefacts treated with these alternatives has been observed to be rather inhomogeneous [71]. As such, lactitol and trehalose conservation are rather labour-intensive consolidants in terms of maintaining homogeneity of treated wood, but what of their sustainability?

In the last decade, whey protein has become increasingly interesting as a food additive, improving the texture and nutritional value of a variety of food products [82]. A by-product of whey protein isolate is the milk sugar lactose. The extent of whey protein isolate is such that demand for lactose, a sparsely soluble, low-sweetness sugar, is far outstripped by supply, resulting in large amounts of wastage [82]. Thus, strategies to increase the profitability of lactose by converting it into other high-value products have gained considerable traction. One of these products is lactitol, produced from the catalytic hydrogenation of lactose $[82,83]$. Lactitol is valued for numerous applications, from low-calorie sweetener to emulsifying agents for polymer and surfactant formulations and, of course, bulking agent and cryo-protective [82], for which it is employed in wood conservation. It is difficult to fully assess the sustainability of lactitol being a by-product of the dairy industry, which can range from very environmentally friendly to highly unsustainable. However, as lactose is a low-value by-product of whey protein isolate, the production of lactitol prevents significant amounts of lactose from being destroyed. As such, it can be considered a positive impact. The catalytic hydrogenation of lactose, or the introduction of hydrogen to the carbonyl group of lactose, currently relies on the use of transition metal catalysts, a finite resource, along with high temperatures (110-200 ${ }^{\circ} \mathrm{C}$, catalyst dependent), high pressures (10-60 bar) and up to $6 \mathrm{~h}$ reaction times. This makes it highly energy and resource-intensive. Moreover, only $\mathrm{Ru}$ and $\mathrm{Ni}$ catalysts have been shown to produce highly selective hydrogenations (>90\%), while $\mathrm{Cu}(68 \%)$ and $\mathrm{Pd}(30 \%)$ have much poorer outcomes [82]. Current manufacturing protocols, thus, impact the overall sustainability of lactitol as a wood consolidant. While not widely used for the hydrogenation of lactose, organocatalytic methods need to be introduced more widely in manufacturing protocols to improve the environmental impact of such waste product valorisation. Organocatalysis relies on the use of small-molecule organic catalysts to promote efficient, low energy and low-temperature transformation, and has revolutionised and improved the environmental impact of catalytic processes in the pharmaceutical and fine chemical industries [84]. Hopefully the recent awarding of the 2021 Nobel prize in Chemistry for organocatalysis [85] will further the uptake of this green methodology in more industrial applications, contributing to lower overall emissions, lower finite resource use and lower energy requirements.

Trehalose, another alternative to sucrose, is a disaccharide consisting of two glucose units with a 1,1- $\alpha, \alpha$-glycosidic linkage widely found in several prokaryotes, unicellular organisms, of which bacteria are the best-known members. Its role as a bio-protectant, specifically its ability to protect organisms from the effects of desiccation, as well as its resistance to acidic degradation [86], are the principal reasons for its use in wood conservation. Initial attempts to synthesise trehalose focused on chemical glycosylation pathways, however, the unusual 1,1- $\alpha, \alpha$-glycosidic linkage between the two units of trehalose makes this reaction hard to achieve with high selectivity. A large number of efficient chemoenzymatic trehalose synthesis pathways are known in nature [86], and these have been exploited to make large scale enzymatic synthesis of trehalose a more efficient option for commercial production. In contrast to sucrose, which is extracted, the production of trehalose focuses on enzymatic biotransformation of starch, sucrose, maltose, and maltodextrins. Starch is obtained from the grinding, washing, sieving, and drying of high starch seeds, tubers 
and roots like potatoes, corn, wheat, rice and tapioca, in another energy-intensive process, similar to the extraction of sucrose as described previously. Maltose and maltodextrin are obtained from either the acidic or enzymatic degradation of starch, enzymatic methods being the most resource-efficient. Enzymatic pathways to produce trehalose from starch, sucrose, maltose and maltodextrins stemming from fungi and yeasts (phosphorylase), from mesophilic bacteria (glycosyltransferase-hydrolase) and thermophilic bacteria (trehalose synthase) have been reported in the literature [87]. Two of these methods are used to commercially produce trehalose, the glycosyltransferase-hydrolase and the trehalose synthase route. The two-step nature of the phosphorylase route and the low yields of trehalose have made this route commercially non-viable. The one-step trehalose synthase route, relying on extremophilic bacteria, requires a temperature of $75-85^{\circ} \mathrm{C}$ and the final yields are up to $85 \%$, thus resulting in a more resource-intensive production route. The glycosyltransferase-hydrolase route is the most environmentally benign, despite the two-step procedure, primarily due to the low temperatures required throughout the procedure $\left(35-45^{\circ} \mathrm{C}\right)$. Furthermore, employing enzymes derived from Arthrobacter spp. with corn starch as the substrate, yields of up to $92 \%$ have been reported [87]. Despite the energy-efficient final synthesis step, thought must also be given to the cultivation and extraction of the substrates, as in many of the previous cases.

\subsection{Synthetic Consoldants}

Inhomogeneity, or the difficulty in obtaining reproducible treatment standards, has long plagued the use of natural substances as effective consolidants. Thus, when innovations in petroleum refinement and commercial chemical synthesis ushered in the reproducible, large scale, low-cost synthesis of a variety of polymers and polymer precursors in the 1940s, this was seen as a significant benefit to the conservation of heritage wood. While the use of sugars, and oils to a lesser extent, are still popular, the first demonstration of archaeological wood stabilisation using low molecular weight PEG in the late 1950s ushered in a new state-of-the-art for wood conservation. This remains the top choice today, particularly for large artefact conservation. However, methacrylate/acrylate copolymers (e.g., Paraloid B72), melamine-formaldehyde resins (e.g., Kauramin), epoxy resins (e.g., EPO155), and, more recently alkoxysilanes, are also popular. Their various methods of production and their primary applications are discussed below. In comparison to the bio-based consolidants discussed previously, in this section all starting materials are obtained from the petrochemical refining of non-renewable resources and further transformed through synthetic processes to wood consolidants as we are familiar with them.

\subsubsection{Poly(ethylene glycol), PEG}

Poly(ethylene glycol) or PEG is a polyether, a class of polymers in which the repeating unit contains a $\mathrm{C}-\mathrm{O}$ bond, and by far, the most widely used wood consolidant currently available. Although it was first synthesised in the 1850s, its commercialisation in the 1940s under the name Carbowax was the main driver for its widespread use in applications from cosmetics and personal care products, to medicine and wood conservation [12,88-90], among others. The high solubility of low molecular weight PEG derivatives (under $4000 \mathrm{~g} / \mathrm{mol}$ ) in water means that PEG can effectively penetrate wood cells without precipitation of the chains in the wood cell wall, leading to complete replacement of water with non-volatile PEG retaining the wood structure during drying [13]. Moreover, the high monodispersity associated with the production of PEG means that conservation treatment can consist of several different PEGs penetrating different depths of the wood, offering varying degrees of stabilisation. For example, a low viscosity PEG (200-600 g/mol) is generally used to penetrate deep into a wooden object where degradation is generally lower, but water must still be replaced. Whereas higher molecular weight PEGs (1500-4000 g/mol) with higher viscosity and greater mechanical stability are generally used to conserve the more degraded surface wood. 
Synthesis of PEG is carried out on a commercial scale by the ring-opening polymerisation of ethylene oxide (EtO) under cationic or anionic conditions. EtO is industrially produced by the direct oxidation of the petroleum-derived ethylene [91], Scheme 1.

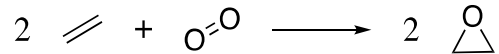

Scheme 1. The direct oxidation of ethylene gives ethylene oxide, the starting material for PEG.

The reaction is carried out using high purity $\mathrm{O}_{2}$ (air is also used in some cases) over a silver catalyst at high temperatures $\left(220-280^{\circ} \mathrm{C}\right)$ and pressures $(1-3 \mathrm{MPa})$ to increase the purity of the yield. On an industrial scale, anionic polymerisations are exploited in which $\mathrm{Na}, \mathrm{K}$ or $\mathrm{Cs}$ alkoxide, hydroxide or carbonates are used to initiate ring-opening of $\mathrm{EtO}$ and chain propagation in polar, aprotic solvents (e.g., THF, dioxane and DMSO) [92]. This is a living polymerisation in which no quenching of the reaction occurs. Living polymerisations are characterised by a fast rate of chain initiation with a low rate of chain propagation and no chain termination or chain transfer, meaning a more controlled growth of polymer chains and a less polydisperse chain length distribution [93]. Using this methodology, PEG chains of specific molecule weights can be synthesised. While no external heat is required to start the reaction, the use of toxic, petrochemically obtained starting materials and solvents like THF and dioxane, and the need to dispose of these waste solvents after PEG synthesis, contribute to the negative environmental impact of PEG production.

\subsubsection{Methacrylate and Acrylate Copolymers}

Acrylates and methacrylates are also a variety of polyether known primarily for their use in cosmetics and adhesives. Copolymers of methyl acrylate and ethyl methacrylate are used in wood conservation under the trade name Paraloid B-72 [20]. A range of additional Paraloid variants exist in which the ethyl methacrylate is replaced by methyl methacrylate (B-82), butyl methacrylate (B-66) or isobutyl methacrylate (B-67) [94,95]. These low molecular weight copolymers with high photo and thermal stability are used to improve the dimensional stability of wood and the aesthetic quality of wooden artefacts. Their insolubility in water means they must be applied to wood in organic solvents, most commonly acetone or toluene.

Standard commercial production of methyl acrylate uses acrylic acid as a feedstock, obtained from the oxidation of propylene from petroleum refining, Scheme 2a. This is then esterified with methanol, produced from the energy-intensive catalytic reduction of syngas (Scheme 2b, [96]), under acid conditions (e.g., sulfuric or para-toluenesulfonic acid) at elevated temperatures (Scheme 2c) [96].

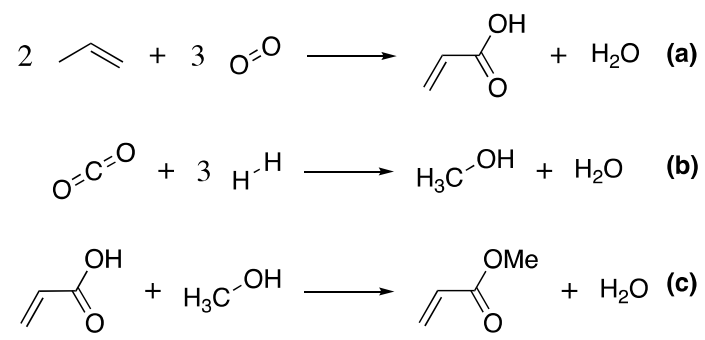

Scheme 2. The main reactions resulting in the production of methyl acrylate, (a) the synthesis of acrylic acid, (b) the production of methanol and (c) the esterification of acrylic acid.

Methacrylates are prepared from methacrylic acid (MAA) [97]. MAA is produced in a multi-step process involving the reaction of acetone with sodium cyanide at $40{ }^{\circ} \mathrm{C}$ to give acetone cyanohydrin (Scheme 3a), which is converted to methacrylamide sulfate (Scheme $3 \mathrm{~b}$ ) by reaction with sulfuric acid at $180^{\circ} \mathrm{C}$ and finally hydrolysed to give MAA (Scheme 3c). 


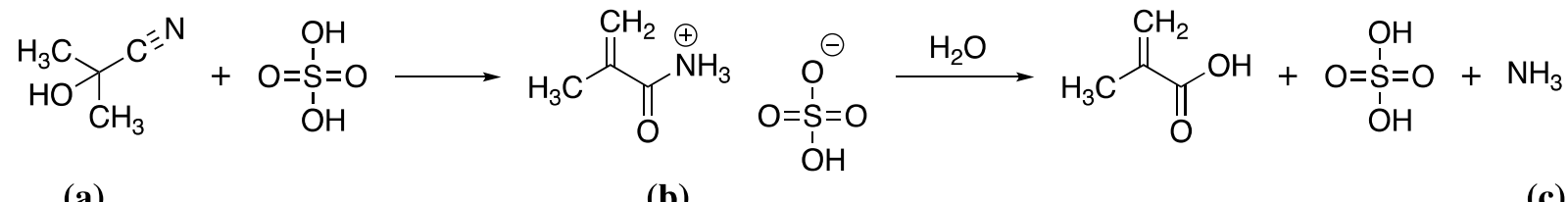

Scheme 3. The reaction of acetone cyanohydrin (a) with sulfuric acid to give methacrylamide sulfate (b) as an intermediate which is then hydrolysed to methacrylic acid (c).

This last step can be replaced with an esterification reaction to directly give methyl methacrylate. The production of ethyl, butyl or isobutyl methacrylate requires the further reaction of methacrylic acid with the corresponding alcohol. The preparation of the copolymers that make up the Paraloid B family of consolidants is carried out by freeradical polymerization in a polar solvent using an initiator that generates free radicals upon heating or irradiation with UV light, such as azobisisobutyronitrile (AIBN) or benzoyl peroxide [98]. This initiator generates radicals on the acrylate and methacrylate units by charge transfer allowing chain propagation. This continues until the desired molecular weight has been reached, at which point copolymers are precipitated in a polar solvent terminating the chains. The multi-step nature of the methacrylate production, the high energy input required, as well as the use of large quantities of acid and polar solvents that are produced from finite resources and must be incinerated to dispose of safely makes the production of acrylate-methacrylate copolymers highly resource inefficient. The further requirement to introduce these consolidants into the wood in organic solvents, generally derived from fossil-based resources further increases the negative environmental impact of the use of these consolidants

\subsubsection{Aminoplasts}

Aminoplasts are thermosetting polymers formed by condensation reactions, of which there are two main types-urea-formaldehyde and melamine-formaldehyde resins. Both resins have been used in wood conservation in the past. However, issues with the toxicity of urea-formaldehyde have led to its replacement with the less toxic melamine-formaldehyde, marketed under the name Kauramin [3]. This is one of few commonly used non-reversible wood consolidants. As such it is generally reserved for the most significantly degraded wood requiring consolidants of greater mechanically stability than is provided with standard PEG or bio-based consolidants. The low molecular weight of the monomers means MF consolidants can penetrate deeply into the wood leaving a rigid 3D polymer network after polymerisation. MF resin synthesis requires the pre-synthesis of both melamine and formaldehyde [99]. Commercial melamine production requires urea as a feedstock. Urea is produced by the high temperature $\left(180-210{ }^{\circ} \mathrm{C}\right)$, high pressure (150 bar) reaction of ammonia $\left(\mathrm{NH}_{3}\right)$ and carbon dioxide $\left(\mathrm{CO}_{2}\right)$ forming ammonium carbamate, which is then dehydrated to urea [100]. Urea is then heated to cause decomposition to cyanic acid and ammonia [101]. Cyanuric acid is formed from the polymerisation of cyanic acid, which condenses with the evolved ammonia to form melamine. The off-gas from the melamine production contains such large quantities of ammonia that it is often funnelled off to create feedstock for the further production of urea, helping to reduce the environmental impact of the production cycle, even if only to a small degree. Formaldehyde is produced by the catalytic oxidation of methanol over a silver metal catalyst at $650{ }^{\circ} \mathrm{C}$ [102]. Methylolation or the formation of MF pre-polymer is carried out by mixing melamine with formaldehyde in a 1:6 ratio at approximately $60{ }^{\circ} \mathrm{C}$ (Scheme 4a) [99]. 
<smiles>CCCCCCCC=O</smiles>

(a)

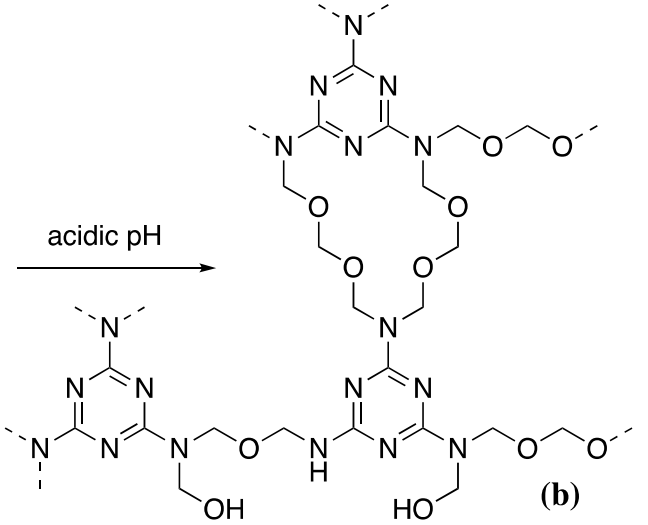

(b)

Scheme 4. The condensation of melamine and formaldehyde to give the prepolymer (a), followed by polymerisation at acidic $\mathrm{pH}$ to give the network structure (b).

This pre-polymer is then infiltrated into the wood over several days/weeks with $\mathrm{pH}$ maintained at 8.5 to ensure no unwanted polymerisation of the pre-polymer occurs. This is generally done with triethanolamine. Once the wood has been completely infiltrated, the $\mathrm{pH}$ is allowed to drop to acidic $\mathrm{pH}$ starting the condensation reaction that produces the MF resin in situ (Scheme 4b). In industrial settings, this would be done by thermal polymerisation to increase reaction efficiency. The entire production process is resource, energy, and labour intensive from the initial preparation of urea to the final MF polymerisation within the wood.

\subsubsection{Epoxy Resins}

Epoxy resins are another non-reversible treatment, that have primarily been used to repair fragile wood surfaces. Their high viscosity makes infiltration of the wood structure impossible, as such epoxy resins are generally confined to surface work. They are also thermosetting polymers that can be homopolymerised to create pure epoxy resins or cross-linked with a range of curing agents, including polyfunctional amines, acids, acid anhydrides, alcohols, phenols and thiols [103]. The most common system, and the one found in most epoxy resins used in wood conservation, are polyfunctional amines. Thus, heteropolymers of epoxies cross-linked by amine curing agents will be the focus of this discussion. Like MF, epoxy resins are a two-part system containing an epoxy pre-polymer and, typically an amine cross-linking unit. The most commonly used epoxy prepolymer is bisphenol A diglycidyl ether (DGEBA) formed from the reaction of bisphenol A (BPA) and epichlorohydrin (Scheme 5).

2<smiles>[CH2-]CC1CO1</smiles><smiles>CC(C)(c1ccc(O)cc1)c1ccc(O)cc1</smiles><smiles>CC(C)(c1ccc(OCC2CO2)cc1)c1ccc(OCC2CO2)cc1</smiles>

Scheme 5. The reaction of bisphenol A with epichlorohydrin to give DGEBA.

Traditionally, allyl chloride is reacted with hypochlorous acid to give two isomeric dichloropropanols, which are treated with $\mathrm{NaOH}$ to give epichlorohydrin, salt and water [104]. Allyl chloride is produced from the high-temperature chlorination of propylene from petroleum refining [105]. The reaction must be carried out over $500^{\circ} \mathrm{C}$ to produce allyl chloride, lower temperature reactions result in 1,2-dichloropropane as the main reaction product. Hypochlorous acid is produced by the electrolysis of saline solutions [106]. Thus, just to reach the stage of epichlorohydrin production requires a significant amount of inputted energy, in the form of both electricity and heat. The production of BPA involves the condensation of acetone with 2 equivalents of phenol in the presence of a strong acid. Both 
acetone and phenol are produced by the cumene process [107], also known as the Hock rearrangement, where benzene is alkylated by propylene, both from petroleum refining, to form isopropylbenzene (cumene) which is then oxidized by air to give acetone and phenol. These are often directly further reacted with a strong acid to produce BPA without further purification. To create the epoxidized DGEBA, BPA is alkylated by epichlorohydrin, this results in the epoxy component of the standard two-barrel resin syringe. In addition to the heavy usage of hazardous chemicals that require specific disposal protocols, and a large energy and resource input, there are significant concerns about the use of BPA. Since the 1990s, BPA has been suspected to be an endocrine disruptor [108,109]. These chemicals disrupt natural hormone production leading to cancers and birth defects, among others. As such, BPA is often replaced by BPS or bisphenol sulfone, in which the starting material for the BP production is a sulfone instead of acetone. However, the process is equally resource-intensive and there are additional health concerns related to the use of BPS which does not significantly improve the impact of the process.

As mentioned previously, polyamines are the most common curing agents for epoxy resins. This family of compounds is extremely large, comprising both aliphatic and aromatic polyamines, of which there are at least 25 commercially available products. Thus, a detailed discussion of their synthesis is not feasible within the context of this review. However, a summary of the basic protocol for some of the simpler aliphatic polyamines will be given to illustrate the process. One common polyamine hardener is triethylenetetramine (TETA), with a curing time of approximately $30 \mathrm{~min}$. It is produced from heating ethylene diamine or mixtures of ethanolamine and ammonia (which react when heated to form ethylene diamine) over a metal oxide catalyst [110]. If the ethylene diamine route is followed, ethylene diamine must be produced by the chlorination of ethylene to produce 1,2-dichloroethane, followed by reaction of the 1,2-dichloroethane with ammonia at $180{ }^{\circ} \mathrm{C}$ under pressure in aqueous media (Scheme $6 \mathrm{a}$ ). Within the second route, ethanolamine must first be formed by the reaction of ethylene oxide with ammonia (Scheme $6 \mathrm{~b}$ ), which is then further reacted with aqueous ammonia to give ethylene diamine (Scheme 6c). Both routes are not completely selective and give a variety of polyfunctional amines. Like that of the epoxidized component, their production also requires significant heat, energy and resources, leaving a significant environmental impact.

(a)

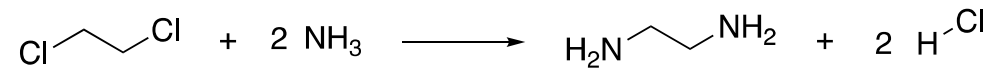

(b)

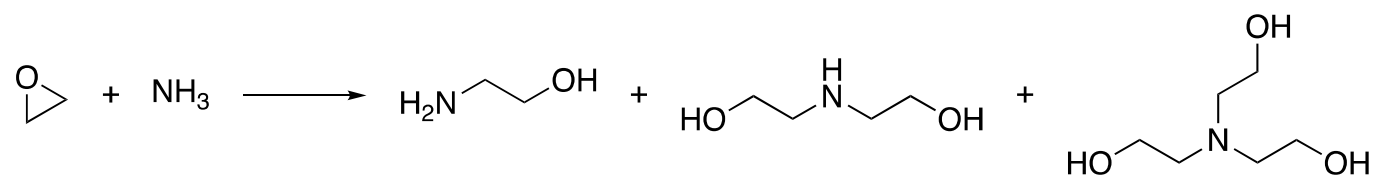

(c)

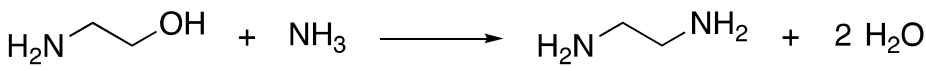

Scheme 6 . The synthesis of ethylenediamine from 1,2-dichloroethane (a) and the ethanolamine (b,c).

\subsubsection{Alkoxysilanes}

Lastly, alkoxysilanes are a relatively new addition to the wood conservation toolkit but have gained increasing popularity in recent years [111-114]. Alkoxysilanes have already been heavily used in the waterproofing and fire retardancy of construction wood, particularly for external applications, so their transfer into the conservation field is not surprising [115-117]. Moreover, they are a major component of almost all commercially available silicon products, thus the synthesis of these polymers is on an industrial scale [118]. The production of alkoxysilanes is one of the most energy-intensive of all the production processes described so far. Mined sand $\left(\mathrm{SiO}_{2}\right)$ is carbothermally reduced at $1900{ }^{\circ} \mathrm{C}$ to give pure silicon $\left(\mathrm{Si}_{\text {met }}\right)$, which is then reacted with the corresponding alcohol to give the desired alkoxysilane [118], Scheme 7. 


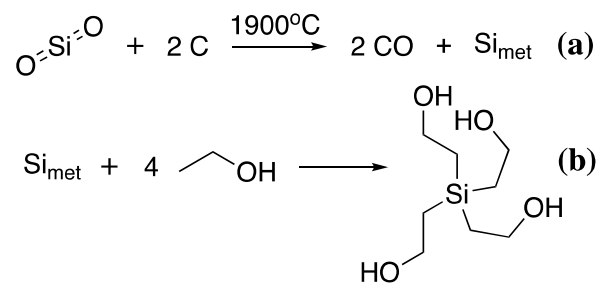

Scheme 7. The synthesis of TEOS from the carbothermal reduction of $\mathrm{SiO}_{2}(\mathbf{a})$, followed by reaction of $\mathrm{Si}_{\text {met }}$ with $\mathrm{EtOH}(\mathbf{b})$.

Thus, to produce the commonly used tetraethoxysilane (TEOS), ethanol or ethylene glycol is reacted with $\mathrm{Si}_{\text {met }}$ with an acidic catalyst. Alcohols for this reaction are either produced from petroleum sources or, in the case of ethylene glycol and ethanol, they can also be produced by fermentation. Alcohols from petroleum refining are produced by acid-catalysed hydration of the corresponding alkene to give the desired alcohol, thus hydration of ethylene produces ethanol. Ethanol can also be produced by fermentation of biomass [119], primarily with the yeast Saccharomyces cerevisiae, which breaks down polysaccharides at $35-40{ }^{\circ} \mathrm{C}$ releasing ethanol and $\mathrm{CO}_{2}$. The disadvantage of this process is the toxicity of ethanol to yeasts meaning that the overall ethanol content of the fermentation broth cannot exceed $18 \%$ by volume. Concentration and distillation must be used to increase overall volume concentrations. Thus, initial savings in energy due to low-temperature fermentations are used to refine the overall product. Currently, the industrial method of choice for ethanol production is country-specific with the US and Brazil favouring biomass-derived ethanol [120], while many other countries favour petroleum refined ethanol. The choice is heavily dependent on the regional costs of oil and grain stocks.

\section{Sustainable Alternatives to Conventional Treatments}

Despite much research in the past decade into new consolidant treatments to replace several state-of-the-art techniques, in particular PEG, there is little uptake of these newer consolidants among heritage institutions. This resistance is, while perhaps frustrating on the part of the conservation scientist, entirely understandable given the one-of-a-kind nature of the wooden objects of interest. New consolidants are often only considered viable alternatives once a large body of data has been collected over many years on the stability, toxicity, and by-products of the process, or when a particular treatment must be replaced due to legislations against its current use.

Due to the long timescale of the transition process, switching to completely new technologies overnight, despite their evident sustainability or other attractive features, is not feasible. As such, the first step in the transition to sustainability is not to switch treatments completely but to search out sustainable alternatives to the treatments currently in use. Thankfully, with more and more interest in the production of bio-based chemicals, there has been a significant increase in the number of commonly used consolidants for which sustainable alternatives exist.

\subsection{Poly(ethylene glycol)}

One of the most relevant sustainable alternatives is the recent increase in production of PEG from bio-based glycerol, produced from the fermentation of the fibrous waste that remains after the extraction of edible crops (e.g., corn, sugarcane). The ability of various species of yeast (e.g., S. cerevisiae) to break down polysaccharides from biomass to produce alcohols has been known for over 150 years [121]. However, in the period after World War II the cost of petroleum refining dropped significantly [122], making the production of alcohols from fermentation a less cost-effective process. Environmental concerns, alongside the desire to valorise the vast amounts of waste from the harvesting of food crops and enhanced yeast variants, have made this approach more attractive in recent decades and has driven a boom in bio-based chemicals, primarily in petroleum poor/agriculturally rich nations, such as Brazil [123]. 
Glycerol, the feedstock required for bio-based PEG, is produced within yeast cells as a reaction to osmotic stress from the environment during fermentation as the concentration of ethanol in the fermentation broth increases. Its production over that of ethanol can be promoted through one of three ways: (1) using more osmotolerant yeast strains that can produce higher quantities of glycerol intercellularly, (2) fermenting at neutral or slightly alkaline $\mathrm{pH}$ enhancing the osmotolerance of the yeast or (3) forming complexes that limit ethanol formation. The primary route to option (3) is by promoting reoxidation of nicotinamide adenine dinucleotide (NADH), a coenzyme necessary for metabolism, whose production consumes glycerol as a cytosolic mechanism to maintain redox balance in the yeast cell [124]. As with the production of ethanol described previously, fermentation is carried out around physiological temperature to maintain the best environment for yeast growth. The glycerol can then be used as the raw material to produce any number of bio-based chemicals, including ethylene glycol (EG). Glycerol undergoes a catalytic dehydrogenation over a transition or noble metal catalyst to give ethylene glycol. The polymerisation of EG to give PEG follows the same process as described in Section 2.2.1 [125]. This bio-derived PEG is already commercially available through several suppliers, marketed as sustainable or green or bio-based PEG (bPEG). While the production of the starting material is inherently more environmentally friendly and sustainable than the derivation of PEG from petroleum refining, the catalytic dehydrogenation step that produces the EG is hugely resource-intensive requiring high temperatures, high pressure, and expensive finite catalysts. However, recent publications on the use of enzymatic cascades to produce ethylene glycol through a multi-step process from monosaccharide feedstocks give hope that the environmental footprint of the bPEG production will reduce further in years to come [126]. It must, however, be kept in mind that while the environmental footprint of the production of the PEG is significantly reduced, the disadvantages associated with the use of conventional PEG (non-recyclable, partially biodegradable at low molecular weights, solid-state ion transport and degradation to acidic by-products over time within the wood structure) will continue to be a feature of the bio-based PEG. However, at the very least choosing to employ bio-based PEG (bPEG) over petroleum-based PEG (pPEG) will contribute to improving sustainability in the conservation laboratory.

\subsection{Epoxies}

The widespread use of epoxies in many fields has also led to a significant increase in research in the production of bio-based epoxy resins (bio-epoxies) and resulted in several commercially available products. However, to date, researchers have struggled to produce bio-based epoxies with similar or better mechanical properties than traditional epoxies. Thus, most epoxies marketed as 'bio-based' are a mixture of renewable and non-renewable epoxies up to a total of $70 \%$ renewably sourced materials, to maintain the desired mechanical properties of the final product. While the creation of bPEG is almost completely focused on production from bio-glycerol, bio-based epoxies have been derived from bio-glycerol, plant oils and wood biomass. The multi-step nature of the epoxy generation process means that different parts of resin production have been reproduced from different bio-resources.

The most common sustainably produced component of epoxy resins is epichlorohydrin. The widespread availability of biomass feedstock for glycerol production means many chemical companies have transitioned to producing epichlorohydrin from bio-glycerol obtained through the same fermentation process as described for bPEG. To obtain epichlorohydrin, bio-glycerol is treated with hydrochloric acid in the presence of a carboxylic acid catalyst to give 1,3-dichlor-2-propanol, releasing water, Scheme 8a. The 1,3-dichlor-2-propanol is then reacted with $\mathrm{NaOH}$ to give epichlorohydrin, Scheme $8 \mathrm{~b}$. 


$$
\underbrace{\mathrm{OH}}_{\mathrm{Cl}}+2 \mathrm{HCl} \stackrel{\mathrm{NCOOH}}{\longrightarrow} \overbrace{\mathrm{Cl}}^{\mathrm{OH}}+\mathrm{H}_{2} \mathrm{O}+\mathrm{NaCl}
$$

Scheme 8. The reaction of bio-glycerol with $\mathrm{HCl}$ to give 1,3-dichlor-2-propanol (a), which is further reacted with $\mathrm{NaOH}$ to give epichlorohydrin (b).

The use of bio-glycerol feedstock improves the sustainability of the epichlorohydrin production, however, the further synthesis of the DGEBA generally follows the traditional route described above. Thus, the overall improvement in the sustainability of the process is limited. Moreover, methods to reduce the use of chlorine in the process need to be advanced.

Environmental concerns relating to the use of BPA have resulted in various biomassderived units being explored to replace BPA and any of its derivatives. The most common of these are lignins and tannins. Both lignins and tannins are macromolecules with multiple phenol residues obtained from the valorisation of woody biomass. The presence of the phenol groups means that they can be reacted with (bio)epichlorohydrin in the presence of $\mathrm{NaOH}$ in a polar solvent at approx. $50^{\circ} \mathrm{C}$ (lignin) [127] or $80{ }^{\circ} \mathrm{C}$ (tannin) [128] to give polyfunctional epoxidised monomers. While this eliminates the hazardous BPA component, and the epichlorohydrin can be derived from bio-glycerol, it does not eliminate the use of chlorine and chlorinated intermediates in the epoxide formation.

Epoxidising plant and vegetable oils to create polyfunctional epoxide monomers are one of the most explored methods of replacing the entire DGEBA component, removing the need for chlorine gas and chlorinated intermediates [45,129-131]. Suitable candidates for epoxidation require the presence of unsaturated fatty acids, i.e., $\mathrm{C}=\mathrm{C}$ bonds where the epoxide ring can be formed. Linseed (75-90\% oleic, $1 \mathrm{C}=\mathrm{C}$, and linolenic acid, $3 \mathrm{C}=\mathrm{C}$ ) and soybean oil ( $~ 85 \%$ oleic, $1 \mathrm{C}=\mathrm{C}$, linoleic, $2 \mathrm{C}=\mathrm{C}$, and linolenic acid, $3 \mathrm{C}=\mathrm{C}$ ) have significantly high concentrations of fatty acids with multiple $\mathrm{C}=\mathrm{C}$ bonds to allow crosslinking of epoxidised oils [132,133]. As such, epoxidised linseed oil (ELO) and epoxidised soybean oil (ESBO) are the most explored and commercially available epoxidised oils used in a variety of paints, coatings and resins. Epoxidation of the oils is generally carried out by reacting hydrogen peroxide with the oil, resulting in the addition of an oxygen atom across the $\mathrm{C}=\mathrm{C}$ creating the epoxide ring. While the renewable sourcing of the oil and the advances in green oil extraction are an improvement on the synthetic DGEBA protocol, the major downside to this process is the production of hydrogen peroxide. $\mathrm{H}_{2} \mathrm{O}_{2}$ is prepared by the anthraquinone process [134], Scheme 9.<smiles>[R]C1=CC2C(=O)c3ccccc3C(=O)C2C=C1</smiles>

Scheme 9. The anthraquinone process.

This involves the high-temperature reduction of anthraquinone to anthrahydroquinone by hydrogenation over a palladium catalyst. The anthrahydroquinone autoxidizes in the presence of oxygen to regenerate the anthraquinone and transfer the $\mathrm{H}_{2}$ to the $\mathrm{O}_{2}$ giving $\mathrm{H}_{2} \mathrm{O}_{2}$. Production of anthraquinone involves the reaction of benzene and ethylene 
from petroleum refining to produce ethylbenzene in a Freidel-Craft reaction over a zeolite catalyst. The ethylbenzene is then dehydrogenated using superheated steam $\left(>600{ }^{\circ} \mathrm{C}\right)$ over an iron catalyst to give styrene. This then undergoes acid catalysed dimerization to 1-methyl-3-phenylindane, which is oxidized to anthraquinone [135], Scheme 10. Thus, once again a large amount of resource and energy-intensive processes are used to produce sustainable alternatives to common consolidants.

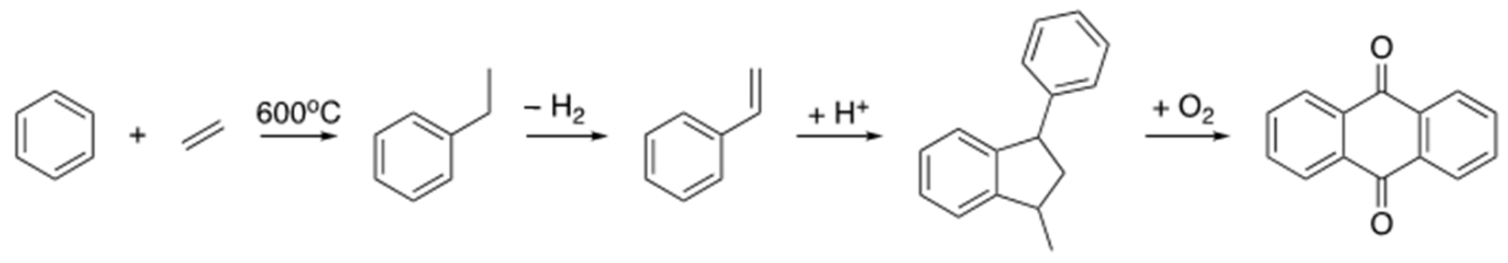

Scheme 10. The multi-step production of anthraquinone from benzene and ethylene.

The final component is the polyamine hardener. This is one of the easiest problems to address given that polyamines are widely found in nature, although they are not yet widely commercialised from bioresources. Until roughly a decade ago little was known about the biosynthetic pathways related to polyamine production, and their low natural abundance made extraction from biomass non-viable from an economic standpoint. However, a better understanding of the biosynthesis of polyamines by bacteria and yeast has led to advances in industrial fermentation of these highly useful molecules and brought their use in bio-based epoxies closer to reality [136]. Several different routes have been explored to engineer the metabolism of bacteria (Escherichia coli and Corynebacterium glutamicum) and yeast (S. cerevisiae) strains that are known to overproduce polyamine precursors (L-arginine, L-lysine and L-ornithine) to directly produce polyamines such as putrescine and cadaverine. These can then be further modified either through biotechnological or chemical means to create a variety of polyamine cross-linkers [137-141]. While the fermentation conditions may differ slightly from bacteria to yeast and depending on the initial feedstock, the clear advantage of this method over the synthetic route is the use of bio-based feedstock and physiological conditions to produce polyamines resulting in a significantly reduced environmental footprint for the process. Although discussed in the literature these advances have not yet made it to the industrial scale for epoxy resin production.

\subsection{Acrylates and Methacrylates}

While no commercially available acrylates or methacrylate currently exist, much research is being carried out to find alternatives to current synthetic procedures. Some of the most promising routes to acrylic acid involve the fermentation of corn starch and vegetable oil to produce glycerol, which is further fermented to lactic acid or 3-hydroxypropionic acid and then dehydrated to give acrylic acid (AA). The disadvantage of this route is the requirement for high-temperature dehydration with heterogeneous or metal oxide catalysts at temperatures approaching $300{ }^{\circ} \mathrm{C}$. Another route to the preparation of bioAA is from poly(3-hydroxybutyrate), which is synthesised bacterially from wastewater and constitutes a waste valorisation route. $\mathrm{P} 3 \mathrm{HB}$ can then be pyrolysed to crotinic acid and then metathesised, a reaction in which two hydrocarbons exchange carbon-carbon bonds in the presence of a metal catalyst [142], with (bio-based) ethylene from bio-glycerol to give propene and acrylic acid [143,144].

With respect to bio-based alternatives to MAA production, which can also then be reacted with the appropriate alcohol to give the desired ester, two main commercially viable routes have been described in the literature, although others exist [143]. The first is the decarboxylation of citric acid (CA), found in large quantities in citrus fruits. It is obtained commercially from the fermentation of sugar cane and beet molasses by Aspergillus niger. $\mathrm{CaOH}$ is added to precipitate the citric acid from the fermentation broth, which must then be neutralised with excess sulfuric acid. The citric acid is then pyrolysed to itaconic anhydride and hydrolysed to itaconic acid. The itaconic acid is then decarboxylated to 
methacrylic acid using various supported transition metal catalysts (although some reports also discuss cheaper solid base catalysts) at temperatures ranging from $200-250{ }^{\circ} \mathrm{C}$, and often high pressure. The disadvantages of this protocol are the multiple steps involved, many of which involve high temperature and pressure reactions, as well as the production of large amounts of gypsum waste from the neutralisation of the $\mathrm{CaOH}$ precipitant. A less energy-intensive approach is the direct production of itaconic acid from the fermentation of glucose with Aspergillus terreus [145]. The itaconic acid is purified by filtration, evaporation, and crystallisation. The drawbacks to this approach are the cost of the substrate and the low yields of itaconic acid compared to the CA approach. However, research is being conducted to investigate cheaper substrates to produce itaconic acid and higher yield, resource-efficient purification techniques. For example, investigations on the use of Aspergillus orzyae with lignin biomass as a substrate detailed the highest yield from solid-state fermentation of IA reported to date [146]. This highlights that as interest increases in bio-based methacrylic acid, and of course acrylics, better and more efficient production will be found.

\subsection{Aminoplasts and Related Consoldants}

Limited options exist in the literature for the sustainable production of MF resins, primarily limited by the sustainable production of melamine. One recent publication discusses the replacement of up to $30 \%$ of the melamine content with bark extractives (i.e., polyphenols from tannins) in an MF resin to give a mixed phenol-melamineformaldehyde resin [147]. However, when the total weight $\%$ of tannin exceeded $30 \mathrm{wt} . \%$ the mechanical properties of the adhesives deteriorated significantly. More promising routes appear to focus on the sustainable production of formaldehyde to improve the overall sustainability of the resins. This generally focuses on the electrolytic production of formaldehyde from seawater and $\mathrm{CO}_{2}$ [148]. Furthermore, several authors report the replacement of formaldehyde with furfural, which can be obtained from renewable resources and reduces the toxic emissions related to formaldehyde over time. Furfural is a furan-based aldehyde produced from the acid-catalysed hydrolysis and dehydration of pentoses obtained from agricultural waste $[149,150]$. This has only been reported for urea-formaldehyde (UF) resins to date, however one could envisage the same potential to replace formaldehyde in MF resins. Up to 50\% of the formaldehyde could reportedly be replaced before the deterioration in the properties of the materials was observed.

The most promising sustainable alternatives to the use of MF resins in conservation are not actually aminoplasts, but phenol-formaldehyde resins. They were previously investigated in wood conservation but were found to have less desirable properties than MF resins. The wide range of polyphenols that can be obtained from wood biomass, specifically from lignins, tannins and suberins, coupled with the ability to sustainably produce, or replace formaldehyde with bio-derived aldehydes means that there is extraordinary potential for a wide variety of new sustainable alternatives to MF resins. The recent hike in prices on $\mathrm{MF}$ by the main producer BASF in response to increasing restrictions on chemicals with a high environmental footprint and no viable sustainable sources will certainly drive research further in this direction [151]. The forerunner in this new category is lignin-formaldehyde resins and several commercially available products exist. A recent study compared the life cycle analysis of three PF resins (with 100\% phenol, 40\% lignin: 60\% phenol and 100\% lignin) and both lignin-containing resins showed significantly improved environmental impacts over the traditionally obtained phenol [152], meaning that even the impact of nonsustainable formaldehyde production is balanced by the renewable sourcing of the lignin component. This highlights the fact that even partially sustainably-sourced consolidants show an improved environmental impact compared to the unsustainable consolidants currently in use. Thanks to the sourcing of lignin, tannin and suberin-based resins from woody biomass, compatibility with wooden artefacts would likely not be a significant issue. The major disadvantage here is that, unlike the other proposed alternatives, switching to lignin-phenol-formaldehyde (LPF) resins is not a simple switch from petroleum sourced to a bio-sourced version of the same chemical. Phenol-formaldehyde resins are 
not extensively used in wood conservation and LPF resins consist of a completely different phenol structure, as such extensive testing would be necessary before the widespread use of lignin-aldehyde resins could be considered. However, it is certainly a development to monitor in coming years with possible further restrictions, and increased costs, in the manufacture of MF resins.

\subsection{Alkoxysilanes}

While alkoxysilanes are a relatively new addition to the wood conservation toolkit, they are a major component in almost all silicon-based commercial products currently available, as such, they are widely synthesised at industrial levels. Despite their widespread usage and the almost century-long search for an alternative to the standard carbothermal process, few match the yields of the current standard [118]. Recently a bio-based alternative has been found that could match the demand for silicon products. Harvesting of rice for food produces a vast amount of waste in the form of rice husks, this is then generally combusted for energy and the residue remaining after pyrolysis is known as rice husk ash (RHA) [153]. Interestingly RHA contains up to $98 \%$ amorphous silica depending on location, rice variety and fertilisers used [154]. This RHA can be depolymerised in a base-catalysed reaction, using $10 \% \mathrm{NaOH}$, in the presence of various diols to give distillable spirocyclic alkoxysilanes [118]. Of particular interest is the ability to react RHA with (bio-based) ethylene glycol to produce a bio-based alternative to the most common alkoxysilane TEOS [118].

A report from 2019 states that Indonesia alone, the world's third-biggest rice producer after China and India, can produce 3.2 million tonnes of silica from RHA per year [154]. The global demand for speciality silicas, i.e., $\mathrm{SiO}_{2}$ used to produce silicon-based polymers, was reported to be 3.9 million tonnes in the same year [155]. Thus, Indonesia alone could satisfy over $80 \%$ of the global demand. Assuming the same conversion from rice production to silica for both China and India for the same year [156], results in approximately 28 million tonnes of silica, 7 times the global demand. Thus, bio-based sources of silica can well match global demand for silicon polymers, meaning a sustainable future for the commercial production of alkoxysilanes may soon become a reality.

\subsection{General Comments}

While interest in developing alternatives to petroleum-based polymers for a variety of applications exists, the number of commercially available products is still rather low. Cost-effectiveness over petroleum-based consolidants may still hinder the switch to biobased consolidants for many institutions. However, the strategy of replacing unsustainable chemicals with sustainable alternatives does not work for all consolidants. It is only possible when considering relatively simple syntheses with easily scalable processes, e.g., the production of PEG, or where the demand across many different fields is so high as to make sustainable synthesis methods a viable commercial option, e.g., bio-based epoxies. For many wood consolidants, this may remain a niche area with a high cost available only to institutions with research laboratories that can create these speciality chemicals on demand for use in limited quantities. Thus, instead of relying on the production of sustainable alternatives to common consolidants that come with the same disposal concerns as their petroleum-based counterparts, we need to start reimagining the entire future of wood consolidation.

\section{Designing the Sustainable Consolidants of the Future}

As mentioned above, simply switching to sustainable alternatives of currently employed consolidants is only part of the solution. While the overall environmental footprint of these bio-derived chemicals is reduced compared to petroleum-based consolidants in terms of production, once produced the bio-based alternatives are just as non-recyclable, toxic and/or non-reparable as the original. Thus, in the long-term, we need to think about the development of more responsible, and circular consolidant solutions, in which none 
of the material becomes waste. This translates to the need for consolidants that can be so well-tailored to the specific degradation issues of the wooden object as to adapt to the changing conservation needs of the wood over time negating the need for repetitive treatment and reducing overall consolidant consumption. Furthermore, unused consolidants within the conservation laboratory should be able to be biodegraded under specific conditions or used to create other materials when they are no longer of use, to reduce the quantities of chemicals going to waste. Development of such materials requires us not only to examine the provenance of the consolidant but its compatibility with the wood matrix, the modification strategies used to create the tailored consolidant behaviour, and the impact these modifications have on the environment. Moreover, the energy use and resource efficiency of the abovementioned strategies are also due to their effect on the overall environmental impact and sustainability of the final consolidant.

Moving away from the current state-of-the-art in consolidants is a much longer-term process and requires a significant amount of development. However, there is already plenty of research underway, particularly around responsive consolidants that could adapt to the changing environment within wooden objects overtime reducing or eliminating the need for repetitive conservation. Several 'new generation' technologies have appeared in the literature in recent years for the treatment of either archaeological or fresh wood with the potential to significantly impact the future of sustainable consolidants. These fall into one of four different categories; (1) bio-based polymers, (2) bio-based capsules with the sustained or triggered release of cargo, (3) bio-based polymer/inorganic NP composites and (4) bio-based polymers with responsive or targeted bulking of wood structure. Many of these new generations of consolidants are based on polysaccharides, although lignin (and lignin-derived polymers), proteins and waxes are also examined.

\subsection{Polymers Extracted from Biomass}

\subsubsection{Proteinaceous Consolidants}

Proteinaceous consolidants, particularly collagen, gelatine, and casein, have been extensively used in the conservation of painted works of art. Their ability to form thin, varnish-like films on drying has been exploited in the cleaning and restoration of painted surfaces. Proteinaceous wood consolidants are rarer, apart from keratin, which has recently been extensively investigated for the conservation of waterlogged wood. Keratin is a structural protein that exists in two forms, $\alpha$-keratin (soft keratin) which is found in the hair, skin, claws (nails), horns and hooves of all vertebrates and $\beta$-keratin (hard keratin) which is found in the feathers and shells of birds and reptiles [157]. Keratin is the third most abundant biopolymer, after cellulose and chitin. Keratin is a significant waste product of the meat-processing industry, with pigskin, for example, containing almost $80 \%$ keratin. Thus, the use of keratin as a wood consolidant represents a valorisation of this waste product and an increase in the sustainability of the meat-processing industry. Despite the use of keratin in wood consolidation and other applications reducing waste from the meat processing industry, the methods used for the extraction of keratin are very resource-intensive, with the potential for significant negative impact when considering the quantities of keratin to be processed. The extraction involves three steps, generally performed at $60{ }^{\circ} \mathrm{C}$ : (1) urea is commonly used to break the covalent bonds in keratin and allow it to be solubilised, (2) a surfactant like sodium dodecyl sulfate is used to disrupt the intermolecular interactions and (3) followed by treatment with thioglycolic acid or mercaptoethanol to cleave the disulphide bond [158]. Sodium dodecyl sulfate (SDS) is produced from the reaction of the petroleum-derived dodecanol, through the procedures previously mentioned in Section 2.2.1 and reacted with sulfur trioxide $\left(\mathrm{SO}_{3}\right)$, produced by the burning of sulfur or pyrite at $400-600{ }^{\circ} \mathrm{C}$ over a silica-supported $\mathrm{V}_{2} \mathrm{O}_{5}$ catalyst activated with $\mathrm{K}_{2} \mathrm{O}$ [159]. Reaction with $\mathrm{SO}_{3}$, or related derivatives of sulfuric acid, adds a sulfonate group (hydrogen lauryl sulfate), which is then neutralised using $\mathrm{NaOH}$ or sodium carbonate [160]. Bio-based SDS can also be produced by hydrolysing plant oils with a high content of $\mathrm{C} 12$ fatty acids, e.g., palm or coconut oil, and then hydrogenating to add the 
sulfonate group, as described previously [161]. The only disadvantage to this approach is that there is a mixture of fatty acids in all plant oils, thus the resulting SDS is a mixture of various sulfonated fatty acids. The final stage in the extraction of keratin involves the use of mercaptoethanol, produced from the reaction of ethylene oxide (described previously) with hydrogen sulphide in the presence of thiodiglycol. $\mathrm{H}_{2} \mathrm{~S}$, a highly toxic gas, is most commonly obtained from the 'sweetening' or refining of natural gas to remove $\mathrm{H}_{2} \mathrm{~S}$ and other organosulfurs [162]. This is generally done by amine scrubbing, an acidbase reaction by which solutions of alkylamines (monoethanolamine, diethanolamine or methyldiethanolamine) are used to solubilise $\mathrm{H}_{2} \mathrm{~S}$ and $\mathrm{CO}_{2}$ and remove them from natural gas, due to the higher solubility of dissociated species. The process is carried out using two linked vessels, an absorber to remove the sour gases and release the sweet gas, and a regenerator to collect the sour gases for further use. The absorber uses temperatures of $30-50{ }^{\circ} \mathrm{C}$ and pressures of $200 \mathrm{~atm}$, while the regenerator uses much higher temperatures $\left(115-126^{\circ} \mathrm{C}\right)$ and low pressures of 1.4-1.7 atm, resulting in an energy-intensive process. Thiodiglycol on the other hand is produced from the hydrolysis of bis(2-chloroethyl) sulphide, also known as Mustard gas [163]. Mustard gas is produced by reacting sulphur dichloride, obtained from the high-temperature chlorination of elemental sulphur, with ethylene from petroleum refining. Thus, while the use of keratin is a sustainable method of reducing waste from meat processing, the methods required to extract the keratin have a very high environmental impact. Recent literature reports detail new, more sustainable methods to extract keratin that give hope for less damaging production in the future. This method involves the use of a highly basic industrial degreaser (containing non-ionic surfactants and $\mathrm{NaOH}$ ) to dissolve the keratin at room temperature within $6 \mathrm{~h}$ with constant stirring, followed by filtration to remove larger particles then two rounds of centrifugation, the second with ultrafiltration to give the pure keratin solution. This was also scaled up to an industrial level and required microfiltration in place of the first round of centrifugation and a final reverse osmosis step to ensure pure keratin was obtained at the end. While these processes are still energy-intensive, there are short $(20 \mathrm{~min})$ and can be potentially powered by renewable energy. Moreover, they use significantly less toxic chemicals derived from petroleum sources, thus constituting an improvement over current methodologies [164].

\subsubsection{Polysaccharides}

In addition to proteins, polysaccharides have also been investigated as new consolidants in the past decade, primarily, chitosan and cellulose (and its derivatives). Cellulose, and then chitin (from which chitosan is derived), are the most abundant biopolymers on earth, thus, are considered an infinitely renewable resource (clearly, with proper management of natural resources). As with keratin, despite the bio-sourcing of the consolidant, the commercial methods of extraction are highly unsustainable. We have already seen from the phenol-formaldehyde resin life cycle analysis, the bio-sourcing of the material made a significant effect on the environmental impact of the material to the extent that it negated much of the poor environmental footprint of the use of formaldehyde and the production of epichlorohydrin. Thus, the use of cellulose and chitosan already represents a positive, sustainable direction for conservation science; however, this does not mean we can completely overlook the negative impact of processing.

While various plants have a high cellulose content, and bacteria are also capable of producing cellulose, commercially cellulose is extracted from wood using the Kraft pulping process. The stability of the wood structure means that the extraction of cellulose is a highly intensive process involving high temperatures, pressures, harsh reagents and produces a significant amount of toxic by-products that require resource-intensive neutralisation to minimise damage to the environment [165]. The process starts with the chipping of wood to increase the surface area for extraction. The wood chips are then digested at elevated temperatures and pressures in an aqueous solution of sulphide and sodium hydroxide to remove the alkaline sensitive lignins that bind the cellulose in the wood matrix. The pulp is then washed repeatedly to remove the pulping liquor, pressed, and dried to obtain pure 
cellulose. The pulping liquor is collected and concentrated, and then fired to remove the organics and regenerate the sodium sulphide from sodium sulfate. It is from this step that lignin can be recovered for further use. The inorganic chemicals from the pulping process remain as smelt after pyrolysis. These are recovered, resolubilised in water and treated with calcium oxide to regenerate the original 'white' liquor to start the pulping again. The spent $\mathrm{CaO}$ (mud) from this step is calcined to regenerate $\mathrm{CaO}$ for repeated use. While some energy requirements are met by the heat generated by pyrolysis and calcining steps within the process, the Kraft process relies heavily on additional energy primarily from finite resources. Switching to renewable energy sources would have a positive impact on the overall environmental footprint but there is still significant use of harsh chemicals, high temperatures and pressures that result in a negative environmental impact. The production of large amounts of sulphur-containing compounds that must be treated to prevent emission into the environment, adds to the high cost of this process [165]. Thus, sustainable processing techniques are urgently needed to improve the impact of cellulose extraction.

One alternative is the use of ionic liquids to extract cellulose from sawdust. Ionic liquids are molten salts with a low glass transition temperature (generally lower than $100{ }^{\circ} \mathrm{C}$ ) [166]. They have many advantages including chemical and thermal stability, environmentally friendly production, and recyclability. Several ILs have been shown to dissolve wood, producing pure cellulose in 3-6 h with the full recovery of the IL after processing under mild conditions [167-174]. With ILs being composed entirely of anions and cations, thus, being good conductors of microwave irradiation, modifications to processing methods to include microwave irradiation of the wood during solubilisation has been shown to reduce processing times from hours to minutes [166]. However, despite the mild dissolution of cellulose and their general perception as environmentally friendly solvents, questions remain about the environmental and health impact of the use of ionic liquids preventing their scale up to commercial applications [173].

A more promising approach is the industrial-scale production of bacterial cellulose (BC). Bacteria from a number of genera have been explored for the production of cellulose from agricultural and industrial waste, specifically, Gluconacetobacter, Aerobacter, Rhizobium, Sarcina, Azotobacter, Agrobacterium, Pseudomonas and Alcaligenes, of which G. xylinus produces the most efficient transition to BC from any number of substrates $[175,176]$. The biosynthetic production of celluloses from bacteria involves two steps, the intracellular polymerisation of glucose into cellulose polymers (the product of four enzymes catalysed reactions $[177,178])$, the cellulose polymers are then ejected from the cell and self-assemble into cellulose fibrils $[175,179]$. Fermentation of BC has already been demonstrated on an industrial scale, and with the potential to use a wide variety of agricultural and industrial waste as feedstocks, vast quantities of BC can be produced, creating a very sustainable source of cellulose that also reduces biological matter waste [180]. More recently, several groups have reported a cell-free enzyme system to produce BC with the potential to generate even higher yields than reported for G. xylinus. The cell-free system is developed from the BC producing strains mentioned above, however, enzymes and co-factors are extracted from the bacterial cells and used directly in the fermentation broth. This reduces the loss of cellulose polymers that are not properly expelled from the intracellular matrix, increasing overall yields $[181,182]$. The only limitation that can be envisaged is that this microbial system produces cellulose nanofibrils (CNFs)/nanocrystals (CNCs) directly after the production of cellulose polymers. In wood conservation, while cellulose polymers and their derivatives have been shown to have great potential, CNCs have not been well studied and in some cases have been shown to achieve poor results due to a filtering effect of the CNCs by the wood structure [183]. As such, they have been primarily used to reinforce the mechanical properties of wood adhesives. Thus, it will be necessary to design methodologies by which the fermentation can be stopped before the assembly of cellulose polymers or by adding additional organisms that inhibit self-assembly to ensure 
large quantities of sustainably sourced cellulose polymers can be made available for wood conservation applications from this method.

Another popular polysaccharide derivative is chitosan, derived from chitin. Chitin is found in the exoskeletons of various invertebrates, primarily shellfish and insects, as well as in mushrooms. On a commercial scale, chitin is primarily extracted from the shells of crustaceans as a valorisation of waste from the fishing and food industries. To extract the chitin, shells are subjected to acid treatment with dilute hydrochloric acid to remove the calcium carbonate, this is followed by a neutralisation step with pure water to remove acid before alkaline treatment with dilute $\mathrm{NaOH}$ to remove the proteins. Again, the materials must be neutralised by extensive washing with pure water. Depending on the source of the chitin, this might be followed by a decolourisation step to remove pigments remaining in the chitin solution $[184,185]$. The pure chitin is finally deacetylated by treatment with concentrated $\mathrm{NaOH}$ or $\mathrm{KOH}$ at high temperatures before copious washing and drying to give chitosan [186]. Despite the natural source of chitosan, the extraction process is quite expensive, uses harsh chemicals and is very water-intensive, as such methods to improve the extraction process are necessary to reduce the environmental impact of chitosan production. While this is the standard commercial extraction procedure, research is already progressing in the development of milder extraction methods to improve the overall sustainability of chitosan extraction. One of the primary alternatives involves microbial bioprocessing [187]. In recent studies, researchers have optimised the activity of two bacterial strains, a protease producing strain to deproteinise the shells, and a lactic acid-producing strain to dissolve calcium carbonate. The processing generally involves the following steps: (1) washing and dehydration of the shells at $60^{\circ} \mathrm{C}$, (2) grinding, (3) enzymatic deproteinization of the shell powder by proteases, and (4) demineralisation of the $\mathrm{CaCO}_{3}$ by lactic acid, leaving pure chitin. A variety of bacterial strains have been explored including Alcaligenes faecalis S3, Bacillus subtilis, B. cereus, B. licheniformis, and Teredinibacter turnerae to produce proteases for the removal of proteins [187-192], whereas lactic acid production has been derived from the activity of Bacillus coagulans L2, Lactobacillus plantarum, Pseudomonas spp., Lactococcus lactis and Gluconobacter oxydans [187,189-192]. Initial attempts at microbial processing reported a two-step procedure involving a deproteinisation step followed by demineralisation. However, several groups have now reported high yields of pure chitin from co-fermentation, further improving the efficiency of the process $[188,189,191]$. Regardless of the number of steps, the overall energy and water usage related to microbial processing is significantly reduced over the commercial process, highlighting a future method to improve the sustainability of chitin extraction.

\subsubsection{Lignin}

A final biomass-derived polymer is lignin. Lignin can be obtained from the Kraft pulping process described above by the addition of $\mathrm{CO}_{2}$ or $\mathrm{NaOH}$ at $\mathrm{pH} 9-10$ to the black liquor retained after cellulose is removed. This retrieves $80 \%$ of the lignins, which can then be purified into lignin chemicals [193]. This lignin is often heavily sulfonated or otherwise modified during the extraction process [194,195]. Lignin for use in adhesives and varnishes, and thus, wood consolidation, is more commonly obtained through the organosolv process [196]. This produces lignins that maintain more of their original structure with no sulphur content [194,195]. Organosolv lignin is obtained by a two-step treatment of woody biomass with weak and strong acids in organic solvents (generally ethanol/water mixtures) at temperatures up to $200^{\circ} \mathrm{C}$. Examples include mixtures of formic and acetic acid in water for the first step at lower temperatures (50-100 ${ }^{\circ} \mathrm{C}$ ) and sulfuric acid/ethanol/water or peroxyformic acid/peroxyacetic acid/water at higher temperatures (80-200 ${ }^{\circ} \mathrm{C}$ ) [197-199]. The organosolv method allows for easier separation of the cellulose and lignin phases, from which the lignin can be extracted by neutralisation and evaporation. The primary uses of these extracted lignins are in the preparation of lignin-based epoxies as described in the previous chapter. However, more recently lignin nanoparticles (LNPs) as consolidants have been investigated in the literature [183]. These were prepared by an 'anti- 
solvent' process in which lignin in a mixed solution of $\mathrm{NaOH}$, dioxane/water and DMSO from the extraction process was dialysed against water to generate LNPs of 40-120 nm diameter [200]. Unfortunately, these LNPs were not found to be particularly successful at infiltrating the wood structure at standard temperature and pressure, managing to penetrate to a depth of just $1 \mathrm{~mm}$. This is similar to the issues observed with consolidation with CNCs. However, these LNPs are interestingly hollow and could be used instead to prepare encapsulated consolidants, with better environmental footprints, as discussed in more detail in the following section.

\subsection{Encapsulated Consolidants with Sustained or Triggered Release}

One of the first examples of encapsulation of wood treatments was the use of gelatine and, later, chitosan nanocapsules to release fungicides within a wooden structure as a function of compressive stress. While this type of consolidant was employed in the treatment of construction wood, applications in heritage wood conservation are easily envisaged. Biocides are applied in large quantities during the conservation of waterlogged wood to prevent bacterial growth within the treated artefact, particularly with PEG consolidants that are hygroscopic and not naturally resistant to bacterial degradation. To ensure adequate penetration of the biocide within the entire wooden object, it is generally applied in excess. This leads to the use of excessively large quantities of petroleum-based chemical biocides that must be incinerated after use to avoid pollution of waterways, which is in itself a highly unsustainable practice. Moreover, the public health considerations of the leaching of biocides from the treated wood, are also a cause for concern. Thus, systems, such as those proposed by Heiden et al. [201-203], in which biocides are encapsulated within bio-based polymer nanoparticles that can be easily transported deep within the wood due to their small size, are more sustainable, and likely more homogeneous, alternatives to the use of large quantities of biocide, that may or may not penetrate the entire depth of the wood. To date, the proposed systems have been synthetic/bio-based hybrids that continuously release low concentrations of biocide over time, with the release profile tailorable as a function of cross-linking density in the outer capsule wall increasing the sustainability of the use of biocides in wood conservation.

One disadvantage to these systems is the sustained release of the biocide over time which is not triggered by any specific interactions. Thus, a biocide may be released in the wood when and where it is not required, leading to the unnecessary use of, albeit smaller quantities of, biocides. However, the most recent iteration of the encapsulation system employs Kraft lignin to create the nanoparticle structure that contains a fungicide, opening up the possibility of triggered release of the contents of the lignin-nanocapsule by fungal lignase produced in the vicinity of the nanocapsule. This system has already been successfully demonstrated in planta [204,205] and could significantly increase the sustainability of biocide use in heritage wood conservation. Another example of lignin nanocapsules with controlled release based on $\mathrm{pH}$ has also recently been described [206]. Such a system could be even more generally useful for the reduction of consolidant usage, contributing to more sustainable conservation practices. As wood degrades, the $\mathrm{pH}$ of the environment changes significantly. For example, the $\mathrm{pH}$ of fresh oak wood is approximately 4.5, while fresh pine is approximately $\mathrm{pH} 5.5$ [207]. However, as wood degrades the $\mathrm{pH}$ can drop to between $0-4$, damaging the acid-sensitive chitosan and reducing the mechanical stability of the wood. Moreover, large-scale use of basic treatments can damage the alkalinesensitive lignin remaining in the wooden object, which often maintains the structural integrity of heavily degraded wooden objects, as cellulose is generally the first part of the wood to be degraded under 'normal' conditions. A bio-based $\mathrm{pH}$-sensitive nanocapsule containing a wood stabilising or deacidification agent could then be tailored to release consolidant only in low $\mathrm{pH}$ environments, meaning consolidants are only released into the wood when necessary, reducing the overall use of consolidants and elongating the period over which embedded consolidants are functional. Furthermore, localised use of 
neutralisation agents would prevent largescale damage to the structural lignin components enhancing the overall mechanical stability of the artefact.

\subsection{Organic-Inorganic Composites}

A further development in sustainable consolidants are composite organic/inorganic treatments, using a range of bio-based polymers and resins embedded with halloysite $\left(\mathrm{Al}_{2} \mathrm{Si}_{2} \mathrm{O}_{5}(\mathrm{OH})_{4}\right)$ nanotubes $(\mathrm{HNTs})$. Halloysite nanotubes have attracted much attention in recent years in many fields, e.g., the pharmaceutical and construction industries, with their low cost, and high natural abundance in volcanic soils, high mechanical strength, ease of functionalisation and ability to store cargo within their internal cavity. For example, HNTs have been shown to significantly improve the sustainability of concrete production with similar mechanical properties when 10\% Portland Cement was replaced with halloysite clay, due to its significantly lower calcining temperature contributing to a reduction in the overall emission of greenhouse gases [208]. Thus, the use of HNTs could be a more sustainable treatment option in comparison with standard inorganic nanoparticles, which are rather energy-intensive in their preparation. Cavallaro, Lazzara and co-workers have been pioneering these natural resin/HNT composites in conservation science for several years and have made great advances [209-213]. Their initial work focused on the use of beeswax/HNT composites to improve the shrinkage upon drying and the mechanical stability of heavily degraded wood. The mechanical strength of the treated objects was found to be independent of temperature at HNT concentrations above $60 \%$ and at temperatures below $70^{\circ} \mathrm{C}$ ensuring that warming of the wax did not result in a decrease in mechanical properties [209]. This is likely due to the formation of 3D networks of HNTs within the matrix that contribute to excellent mechanical properties. This system has been refined more recently to include examples of esterified colophony, pure paraffin wax and paraffin wax Pickering emulsions as matrices for the HNTs, all with promising results, highlighting their potential to be more extensively exploited in wood conservation [210,211,213-215].

Another interesting aspect of HNTs is that, in a similar way to the bio-based nanocapsules described above, their internal cavities can easily be functionalised to provide sustained or controlled release of molecules over time. This has been demonstrated with a variety of drug molecules stored in the cavity [216-220] and could easily be envisaged for the sustained or controlled release of biocides or additional consolidants within the wood structure. An example of this is the encapsulation of anti-oxidants within the HNTs, which are then embedded in a chitosan/pectin matrix for the conservation of works of art [212]. The success of this method demonstrates the possibility that wood consolidants based on HNTs embedded in a waxy matrix could also be doped with biocides or fungicides as described for the nanocapsules above providing a sustainable mechanical stabiliser that would combat biological activity in the wood over time. Moreover, the cavity can also be functionalised to absorb molecules from the environment, creating an interesting scenario for conservation scientists? Could the internal surface of the HNTs be functionalised to absorb acids from the environment preventing their further action on the already fragile wood structure? However, what happens when the internal cavity is full? Could the internal structure be functionalised in such a way that absorbed molecules could be broken down into non-toxic components and released from the wood, ensuring continued activity over time? Hopefully, an answer to these questions will be possible in the coming years, as such a regenerative consolidant could be a significant boon to sustainable consolidant development.

\subsection{Bio-Inspired Consolidants}

A major benefit to the future of sustainable consolidants would be the advent of more adaptable, responsive and/or targeted consolidants. These are often referred to as bio-inspired consolidants, replicating some natural function within the consolidant. For example, replicating the ability of siderophores to trap and deactivate catalytic iron to hinder further iron catalysed wood degradation [221]. Consolidants derived from bio- 
resources and able to respond to the changing conservation status of an object over time would mean a far reduced environmental footprint to produce these materials and less or no need for retreatment, significantly reducing the quantities of consolidant employed.

One of the first examples of adaptable consolidants was the PolyCatNap hydrogel consolidant [221]. PolyCatNap is a 3D network of multiply functionalised chitosan and guar gum. Guar gum is a galactomannan polysaccharide extracted from the seeds of the guar bean (Cyamopsis tetragonoloba L.) by a mechanical process involving roasting, sieving, and polishing [222]. Sieving results in the separation of guar gums of different particle sizes, which result in different viscosity preparations. To create the 3D network, chitosan was covalently modified under room temperature and aqueous conditions with either naphthol or catechol units, while guar was dynamically covalently modified with methyl viologen units. The three polymers were mixed in water, and the addition of the supramolecular host cucurbit[8]uril (CB[8]) allowed the formation of ternary complexes between the naphthol and MV units within the $\mathrm{CB}[8]$ cavity creating a basic 3D structure of the network. In wood with a high $\mathrm{Fe}^{3+}$ concentration, the presence of catechol-functionalised chains provided an additional orthogonal cross-link between 3 catechol functionalised chains and the $\mathrm{Fe}^{3+}$, deactivating the catalytic properties of the iron and increasing the mechanical strength of the network. This allows the consolidant to adapt to the changing $\mathrm{Fe}^{3+}$ concentration in the wood and the possible weakening of the wood over time because of $\mathrm{Fe}^{3+}$ presence. The consolidant was shown to have no reaction to $\mathrm{Fe}^{2+}$ in the wood samples, displaying selective cross-linking properties. Clearly, with the synthesis of naphthol, catechol and methyl viologen requiring the use of petroleum-derived starting materials and high energy/resource processes the sustainability of this system is not optimal. Recent developments in this technology have shown, however, that various units could be replaced with bio-derived molecules, enhancing the sustainability of the system. For example, coumarin derivatives that could photo or thermally dimerise to create the basic host-guest cross-links could be employed in place of both naphthol and methyl viologen and dopamine could replace catechol creating a completely bio-based version of this system. What is clear though, is that the advantage of this type of consolidant is that it reacts to the changing chemical environment around it. As $\mathrm{Fe}^{2+}$ becomes reduced to $\mathrm{Fe}^{3+}$, either by chemical or microbial action the resulting $\mathrm{Fe}^{3+}$ becomes bound within the consolidant preventing additional catalytic action that will further degrade the cellulosic component of the wood. As such, the consolidant can recognise and adapt to changes in the environment, reducing the need for repetitive consolidation as $\mathrm{Fe}^{3+}$ concentration increases. Such adaptable systems are key to the future of sustainable wood consolidant, assuming we can learn how to also produce them with a minimal environmental footprint.

Interestingly, much of the discussion of alternative consolidants have focused on materials that can replace what is missing from the degraded wood, primarily cellulose, rather than targeting and strengthening what is still there, generally lignin. Lignin is often described as the structural component of the wood. While it generally remains long after celluloses have been degraded, it is often significantly altered [223]. Thus, consolidants that target the lignin component of the wood can be very beneficial to the long-term stability of an artefact, however, such consolidants are quite rare. Several lignin-based consolidants are discussed in previous sections, but their purpose is not specifically to target lignin, rather to reduce the toxicity and improve the sustainability of standard consolidants that are already on the market. However, some work has been done to develop targeted lignin consolidants, which have the potential to significantly improve the stability of heavily degraded wood [224]. Currently, heavily degraded wood is conserved with Kauramin, a highly unsustainable synthetic polymer that irreversibly polymerises in situ and has limited compatibility with the wood structure that often leads to warping and cracking of treated artefacts. McHale et al. [224] propose synthesising lignin-like oligomers that would target and bulk the lignin matrix, as lignin itself is too bulky to effectively penetrate the wood matrix. Using isoeugenol, propenyl-substituted guaiacol similar to the guaiacol sub-unit of lignin, they reported the synthesis of lignin-like oligomers. Isoeugenol is a 
major component in the essential oils of cloves, cinnamon or ylang-ylang, among others. The oils are extracted by steam distillation and then treated with $\mathrm{NaOH}$ or $\mathrm{KOH}$ to recover eugenol and isoeugenol [225]. The polymerisation of isoeugenol was carried out at room temperature for 2 days in the presence of a copper salen catalyst and $\mathrm{H}_{2} \mathrm{O}_{2}$ at $\mathrm{pH} 10$. The use of copper catalysts does reduce the sustainability of the system. In follow-up work, the authors showed that the synthesis could be catalysed by horseradish peroxidase (HRP) in place of $\mathrm{Cu}$ (salen), significantly improving the environmental impact of the consolidant [226]. Moreover, with this HRP catalyst, a natural producer of $\mathrm{H}_{2} \mathrm{O}_{2}$, the oligomers could be synthesised in situ. The reaction is carried out by immersing the wood in a solution of isoeugenol in ethanol/water. After impregnation of the wood, HRP and $\mathrm{H}_{2} \mathrm{O}_{2}$ were added to start polymerisation, which continued over two weeks. The samples were washed to remove ethanol before freeze-drying. Both the infiltration with oligomers and their in situ polymerisation gave promising results for the conservation of heavily degraded wood. The interaction of the guaiacol derivatives with the lignin enhances the specificity of the polymerisation and the compatibility with the matrix, offering a promising alternative to the use of Kauramin for heavily degraded samples.

The most recent example of bio-inspired consolidant is a terpene polyacrylate treatment derived from the $\alpha$-pinene, a monoterpene extracted from colophony [227]. While this treatment has only been synthesised and not yet tested on wood, it is certainly an interesting proposition and one that merits further investigation. Terpenes perform a natural protective function in wood [228], as such terpene-based consolidants may provide protective functions to degraded wood that are not exploited in the current conservation toolkit. The only potential disadvantage of this system is the heavy use of petroleum-based solvents and reactants to achieve the final terpene polyacrylate. However, advances in the production of acrylates from bioresources, along with more efficient enzymatic catalysis, as discussed in previous sections, and the drive to develop new bio-based solvents for chemical synthesis [229] means that much of the described reaction process could be replaced with bio-derived chemicals improving the overall sustainability of this novel consolidant.

\section{Discussion and Conclusions}

One of the major challenges to the drive for sustainability in the conservation of wooden objects of cultural importance will most likely be the switch away from fossil fuels as energy. With diminishing demand for fossil fuels for energy production, oil extractors are adapting their portfolios to ensure continued income from fossil fuels, albeit from different sources than in the past. Many oil refineries are planning to increase their petrochemical output from under $20 \%$ to between $45-80 \%$, meaning increased production of raw materials for virgin plastics and polymers. Increased production of petrochemicals will also drive down costs, making polymer consolidants derived from biomass less costeffective. This presents a real barrier to change in a sector that is already under-funded and resistant to move away from state-of-the-art due to the as-yet-unknown potential impacts on artefact conservation.

However, we already know our consumption practices are driving irreversible changes in the dynamics of our planet leading to potentially catastrophic consequences, which will heavily impact the conservation of the world's natural heritage and cultural heritage. Extremes in humidity, in particular, will affect wooden heritage to a significant degree meaning an increase in the number of objects requiring active conservation. Thus, the sooner we can enact new conservation practices that focus on the circularity and sustainability of the entire process from the production of the consolidant to treatment of the artefacts, the greater chance we have to reduce the negative impacts of unsustainable consumption on the planet in general. This will require a significant internal change in the museum and institutional protocols with respect to conservation, however, this is not something unfamiliar in this arena. Museums and cultural institutions are uniquely positioned to significantly impact sustainable development goals. Their role as trusted institutions, in particular centres of formal and informal learning, means that by driving change within, 
they can significantly impact change in the wider community. By investing in sustainable conservation practices and making this known to their visitors through awareness and education programmes, they have the potential to influence how their visitors view their own consumption practices. Highlighting the environmental impact of non-sustainable consolidant use and the benefits to the use of bio-based (and preferably dynamic) consolidants that can be reused, recycled, and repaired without significant further resource usage may encourage visitors to examine their own use of sustainable products and effect much wider-reaching change than without such influence from a trusted source. Museums currently do this by choosing renewable energy sources and low-energy ventilation and lighting systems and publicising the use of such, with great effect. What would be the change to petrochemical-based material usage if museums and cultural institutions were to turn their attention to bio-based chemical usage and educate the public about the benefits? Significant testing of long-term stability is required before such circular consolidants are a common part of the conservation toolkit, hence the two-step strategy to achieving truly sustainable conservation processes, but if we do not start now, then when? Alarm bells are already ringing for the future of the planet, the time to make changes for the future and long-term sustainability of conservation practices is now.

Funding: This research received no external funding; however, the APC was kindly funded by the Open Access Fund of the University of Basel Library.

Institutional Review Board Statement: Not applicable.

Informed Consent Statement: Not applicable.

Data Availability Statement: Not applicable.

Acknowledgments: Z. Walsh-Korb acknowledges financial support from the European Union's Horizon 2020 research and innovation programme under the Marie Skłodowska-Curie grant agreement No. 842043 [CatchGel].

Conflicts of Interest: The author declares no conflict of interest.

\section{References}

1. Fratzl, P. Biomimetic materials research: What can we really learn from nature's structural materials? J. R. Soc. Interface 2007, 4, 637-642. [CrossRef]

2. Fratzl, P.; Weinkamer, R. Nature's hierarchical materials. Prog. Mater. Sci. 2007, 52, 1263-1334. [CrossRef]

3. Walsh-Korb, Z.; Avérous, L. Recent developments in the conservation of materials properties of historical wood. Prog. Mater. Sci. 2019, 102, 167-221. [CrossRef]

4. Marais, B.N.; Brischke, C.; Militz, H. Wood durability in terrestrial and aquatic environments-A review of biotic and abiotic influence factors. Wood Mater. Sci. Eng. 2020, 1-24. [CrossRef]

5. Kirker, G.; Winandy, J. Above Ground Deterioration of Wood and Wood-Based Materials. In Deterioration and Protection of Sustainable Biomaterials; Schultz, T.P., Goodell, B., Nicholas, D.D., Eds.; American Chemical Society: Washington, DC, USA, 2014; pp. 113-129. [CrossRef]

6. Jones, J.M.; Heath, K.D.; Ferrer, A.; Brown, S.P.; Canam, T.; Dalling, J.W. Wood decomposition in aquatic and terrestrial ecosystems in the tropics: Contrasting biotic and abiotic processes. FEMS Microbiol. Ecol. 2019, 95, fiy 223. [CrossRef]

7. Kim, Y.; Singh, A.P. Wood as Cultural Heritage Material and its Deterioration by Biotic and Abiotic Agents. In Secondary Xylem Biology; Kim, Y.S., Funada, R., Singh, A.P., Eds.; Academic Press: Cambridge, MA, USA, 2016; Chapter 12; pp. 233-257. [CrossRef]

8. Hocker, E. Maintaining a stable environment: Vasa's new climate-control system. APT Bull. J. Preserv. Technol. 2010, 41, 3-10.

9. Böhm, C.B.; Zehnder, K.; Domeisen, H.; Arnold, A. Climate Control for the Passive Conservation of the Romanesque Painted Wooden Ceiling in the Church of Zillis (Switzerland). Stud. Conserv. 2001, 46, 251-268. [CrossRef]

10. United Nations. Transforming Our World: The 2030 Agenda for Sustainable Development. United Nations: September 2015. Report No.: A/RES/70/1. Available online: https://sustainabledevelopment.un.org/content/documents/21252030\%20Agenda\%20for\% 20Sustainable\%20Development\%20web.pdf (accessed on 22 December 2021).

11. Hocker, E.; Almkvist, G.; Sahlstedt, M. The Vasa experience with polyethylene glycol: A conservator's perspective. J. Cult. Herit. 2012, 13, S175-S182. [CrossRef]

12. Stamm, A.J. Dimensional stabilization of wood with carbowaxes. For. Prod. J. 1956, 846, 1-4.

13. Hoffmann, P. Methods of application of polyethylene glycol. In Conservation of Archaeological Ships and Boats-Personal Experiences; Archetype Publications: London, UK, 2013; pp. 43-80. 
14. Graves, D.J. A comparative study of consolidants for waterlogged wood: Polyethylene glycol, sucrose and silicon oil. SSCR J. News Mag. Scott. Soc. Conserv. Restor. 2004, 15, 13-17.

15. Mortensen, M.N.; Egsgaard, H.; Hvilsted, S.; Shashoua, Y.; Glastrup, J. Characterisation of the polyethylene glycol impregnation of the Swedish warship Vasa and one of the Danish Skuldelev Viking ships. J. Archaeol. Sci. 2007, 34, 1211-1218. [CrossRef]

16. Lionetto, F.; Frigione, M. Effect of novel consolidants on mechanical and absorption properties of deteriorated wood by insect attack. J. Cult. Herit. 2012, 13, 195-203. [CrossRef]

17. Kiliç, N.; Kiliç, A.G. An attenuated total reflection Fourier transform infrared (ATR-FTIR) spectroscopic study of waterlogged woods treated with melamine formaldehyde. Vib. Spectrosc. 2019, 105, 102985. [CrossRef]

18. Christensen, M.; Kutzke, H.; Hansen, F.K. New materials used for the consolidation of archaeological wood-Past attempts, present struggles, and future requirements. J. Cult. Herit. 2012, 13, S183-S190. [CrossRef]

19. Gierlinger, N.; Hansmann, C.; Röder, T.; Sixta, H. Comparison of UV and Confocal Raman Microscopy to Measure the MelamineFormaldehyde Resin Content within Cell Walls of Impregnated Spruce Wood. Holzforschung 2005, 59, 210-213. [CrossRef]

20. Crisci, G.M.; La Russa, M.F.; Malagodi, M.; Ruffolo, S.A. Consolidating properties of Regalrez 1126 and Paraloid B72 applied to wood. J. Cult. Herit. 2010, 11, 304-308. [CrossRef]

21. Traistaru, A.A.T.; Timar, M.C.; Câmpean, M. Studies upon penetration of paraloid B72 into poplar wood by cold immersion treatments. Bull. Transilvania Univ. Brasov For. Wood Ind. Agric. Food Eng. Ser. II 2011, 4, 81.

22. Yadav, V.G.; Yadav, G.D.; Patankar, S.C. The production of fuels and chemicals in the new world: Critical analysis of the choice between crude oil and biomass vis-à-vis sustainability and the environment. Clean Technol. Environ. Policy 2020, 22, 1757-1774. [CrossRef]

23. Klein, D.; Carazo, M.P.; Doelle, M.; Bulmer, J.; Higham, A. The Paris Agreement on Climate Change: Analysis and Commentary; Oxford University Press: Oxford, UK, 2017.

24. Mathy, S.; Menanteau, P.; Criqui, P. After the Paris Agreement: Measuring the Global Decarbonization Wedges from National Energy Scenarios. Ecol. Econ. 2018, 150, 273-289. [CrossRef]

25. Sachs, N.M. The Paris Agreement in the 2020s: Breakdown or Breakup. Ecol. LQ 2019, 46, 865. [CrossRef]

26. Averchenkova, A.; Bassi, S. Beyond the Targets: Assessing the Political Credibility of Pledges for the Paris Agreement; Grantham Research Institute on Climate Change and the Environment, London, UK. 2016. Available online: http://eprints.lse.ac.uk/65670/ (accessed on 22 December 2021).

27. Bataille, C.; Åhman, M.; Neuhoff, K.; Nilsson, L.J.; Fischedick, M.; Lechtenböhmer, S.; Solano-Rodriquez, B.; Denis-Ryan, A.; Stiebert, S.; Waisman, H.; et al. A review of technology and policy deep decarbonization pathway options for making energy-intensive industry production consistent with the Paris Agreement. J. Clean. Prod. 2018, 187, 960-973. [CrossRef]

28. Young, O.R. The Paris Agreement: Destined to succeed or doomed to fail? Polit. Gov. 2016, 4, 124-132. [CrossRef]

29. Ambrose, J.; The Guardian. War on Plastic Waste Faces Setback as Cost of Recycled Material Soars. 13 October 2019. Available online: http:/ / www.theguardian.com/environment/2019/oct/13/war-on-plastic-waste-faces-setback-as-cost-of-recycledmaterial-soars (accessed on 30 November 2021).

30. American Chemical Society. Why the Future of Oil Is in Chemicals, Not Fuels. Available online: https://cen.acs.org/business/ petrochemicals/future-oil-chemicals-fuels/97/i8 (accessed on 31 May 2021).

31. Tooze, A. Why Central Banks Need to Step Up on Global Warming. 20 July 2019. Available online: https:/ / foreignpolicy.com/20 19/07/20/why-central-banks-need-to-step-up-on-global-warming/ (accessed on 30 November 2021).

32. Feldstein, M. Introduction to "The Economics of Art Museums". In The Economics of Art Museums; Feldstein, M., Ed.; University of Chicago Press: Chicago, IL, USA, 1991; pp. 1-12.

33. Bauer, M.D.; Rudebusch, G.D. The Rising Cost of Climate Change: Evidence from the Bond Market. Rev. Econ. Stat. 2021, 1-45. [CrossRef]

34. Xiao, C. Focus on "Biobased", "Biodegradable", \& "Compostable" Plastics. Department of Ecology, State of Washington. Report No.: 14-07-017. 2014. Available online: https:/ / www.bpiworld.org/Resources/Documents/Washington\%20State \%20Biobased\% 20Fact\%20Sheet\%20Aug\%2014.pdf (accessed on 22 December 2021).

35. de Silva, M.; Henderson, J. Sustainability in conservation practice. J. Am. Inst. Conserv. 2011, 34, 5-15. [CrossRef]

36. Unger, A.; Schniewind, A.P.; Unger, W. Conservation of Wood Artifacts: A. Handbook; Springer: Berlin/Heidelberg, Germany, 2001. [CrossRef]

37. Schönemann, A.; Eisbein, M.; Unger, A.; Dell'mour, M.; Frenzel, W.; Kenndler, E. Historic Consolidants for Wooden Works of Art in Saxony-An Investigation by GC-MS and FTIR Analysis. Stud. Conserv. 2008, 53, 118-130. [CrossRef]

38. Schönemann, A.; Edwards, H.G.M. Raman and FTIR microspectroscopic study of the alteration of Chinese tung oil and related drying oils during ageing. Anal. Bioanal. Chem. 2011, 400, 1173-1180. [CrossRef]

39. Schönemann, A.; Frenzel, W.; Unger, A.; Kenndler, E. An Investigation of the Fatty Acid Composition of New and Aged Tung Oil. Stud. Conserv. 2006, 51, 99-110. [CrossRef]

40. Jacobsson, E. Environmental Impact Analysis of Flax Fibre Cultivation for Composite Reinforcement. MSc Thesis, Mid Sweden University, Sundsvall, Sweden, 2018. Available online: https://www.diva-portal.org/smash/get/diva2:1262794/FULLTEXT01. pdf (accessed on 22 December 2021).

41. Heller, K.; Baraniecki, P.; Praczyk, M. Fibre flax cultivation in sustainable agriculture. In Handbook of Natural Fibres; Kozłowski, R.M., Ed.; Woodhead Publishing: Sawston, UK, 2012; Chapter 15; pp. 508-531. [CrossRef] 
42. Kasote, D.M.; Badhe, Y.S.; Hegde, M.V. Effect of mechanical press oil extraction processing on quality of linseed oil. Ind. Crops Prod. 2013, 42, 10-13. [CrossRef]

43. Gros, C.; Lanoisellé, J.-L.; Vorobiev, E. Towards an Alternative Extraction Process for Linseed Oil. Chem. Eng. Res. Des. 2003, 81, 1059-1065. [CrossRef]

44. Kumar, S.P.J.; Prasad, S.R.; Banerjee, R.; Agarwal, D.K.; Kulkarni, K.S.; Ramesh, K.V. Green solvents and technologies for oil extraction from oilseeds. Chem. Cent. J. 2017, 11, 9. [CrossRef]

45. Supanchaiyamat, N.; Shuttleworth, P.S.; Hunt, A.J.; Clark, J.H.; Matharu, A.S. Thermosetting resin based on epoxidised linseed oil and bio-derived crosslinker. Green Chem. 2012, 14, 1759-1765. [CrossRef]

46. Panov, D.; Terziev, N. Durability of epoxi-oil modified and alkoxysilane treated wood in field testing. Bioresources 2015, 10, 13. [CrossRef]

47. Ciesla, W.M. (Ed.) Fruits. In Non-Wood Forest Products from Temperate Broad-Leaved Trees; Food and Agriculture Organization of the United Nations: Rome, Italy, 2002; Chapter 7. Available online: https://www.fao.org/3/y4351e/y4351e0b.htm (accessed on 22 December 2021)

48. Arminger, B.; Jaxel, J.; Bacher, M.; Gindl-Altmutter, W.; Hansmann, C. On the drying behavior of natural oils used for solid wood finishing. Prog. Org. Coat. 2020, 148, 105831. [CrossRef]

49. Tung Oil. Nature 1929, 124, 272-273. [CrossRef]

50. Tung Oil in the United States. Nature 1932, 130, 199. [CrossRef]

51. Shultz, E.B. Fuels and Chemicals from Oilseeds: Technology and Policy Options; CRC Press: Boca Raton, FL, USA, 2019.

52. Zhang, Y.; Li, Y.; Jiang, L.; Tian, C.; Li, J.; Xiao, Z. Potential of Perennial Crop on Environmental Sustainability of Agriculture. Proc. Environ. Sci. 2011, 10, 1141-1147. [CrossRef]

53. Li, Z.; Long, H.; Zhang, L.; Liu, Z.; Cao, H.; Shi, M.; Tan, X. The complete chloroplast genome sequence of tung tree (Vernicia fordii): Organization and phylogenetic relationships with other angiosperms. Sci. Rep. 2017, 7, 1-11. [CrossRef]

54. Hepburn, H.R.; Bernard, R.T.F.; Davidson, B.C.; Muller, W.J.; Lloyd, P.; Kurstjens, S.P.; Vincent, S.L. Synthesis and secretion of beeswax in honeybees. Apidologie 1991, 22, 21-36. [CrossRef]

55. Tinto, W.F.; Elufioye, T.O.; Roach, J. Waxes. In Pharmacognosy; Badal, S., Delgoda, R., Eds.; Academic Press: Cambridge, MA, USA, 2017; Chapter 22; pp. 443-455. [CrossRef]

56. Coppock, R.W. Bee products as nutraceuticals to nutraceuticals for bees. In Nutraceuticals, 2nd ed.; Gupta, R.C., Lall, R., Srivastava, A., Eds.; Academic Press: Cambridge, MA, USA, 2021; Chapter 47 ; pp. 813-833. [CrossRef]

57. The Honey Industry. Available online: https://www.vegansociety.com/go-vegan/why-go-vegan/honey-industry (accessed on 30 November 2021).

58. Brookfield, H.C. Problems of Monoculture and Diversification in a Sugar Island: Mauritius. Econ. Geogr. 1959, 35, 25-40. [CrossRef]

59. Lupupa, T.; Mavimbela, S.; Rossi, A.; Laub, R. From Subsistence Farming to Sugar-Cane Monoculture: Impacts on Agrobiodiversity, Local Knowledge and Food Security; Food and Agriculture Organization of the United Nations: Rome, Italy, 2008. Available online: https:/ / www.fao.org/3/aj042e/aj042e00.htm (accessed on 19 November 2021).

60. Li, X.-F.; Wang, Z.-G.; Bao, X.-G.; Sun, J.-H.; Yang, S.-C.; Wang, P.; Wang, C.-B.; Wu, J.-P.; Liu, X.-R.; Tian, X.-L.; et al. Long-term increased grain yield and soil fertility from intercropping. Nat. Sustain. 2021, 4, 943-950. [CrossRef]

61. Calatayud-Vernich, P.; VanEngelsdorp, D.; Picó, Y. Beeswax cleaning by solvent extraction of pesticides. MethodsX 2019, 6, 980-985. [CrossRef]

62. Sharma, S.C.; Prasad, N.; Pandey, S.K. Status of Resin Tapping and Scope of Improvement: A Review. AMA Agric. Mech. Asia Afr. Lat. Am. 2018, 49, 16-26.

63. Soliño, M.; Yu, T.; Alía, R.; Auñón, F.; Bravo-Oviedo, A.; Chambel, M.R.; de Miguel, J.; Del Río, M.; Justes, A.; Martínez-Jauregui, M.; et al. Resin-tapped pine forests in Spain: Ecological diversity and economic valuation. Sci. Total Environ. 2018, 625, 1146-1155. [CrossRef]

64. Heinze, A.; Kuyper, T.W.; García Barrios, L.E.; Ramírez Marcial, N.; Bongers, F. Tapping into nature's benefits: Values, effort and the struggle to co-produce pine resin. Ecosyst. People 2021, 17, 69-86. [CrossRef]

65. Tomusiak, R.; Magnuszewski, M. Effect of Resin Tapping on Radial Increments of Scots Pine (Pinus sylvestris L.). In TRACE: Tree Rings in Archaeology, Climatology, and Ecology, Proceedings of the DENDROSYMPOSIUM 2008, Zakopane, Poland, 27-30 April 2008; GeoForschungsZentrum: Potsdam, Germany, 2009; Volume 7, pp. 153-157. Available online: https://gfzpublic.gfz-potsdam.de/ rest/items/item_16015_4/component/file_16014/content\#page=153 (accessed on 22 December 2021).

66. Papadopoulos, A.M. Resin tapping history of an Aleppo Pine Forest in central Greece. Open Forensic Sci. J. 2013, 6, 50-53. [CrossRef]

67. Génova, M.; Caminero, L.; Dochao, J. Resin tapping in Pinus pinaster: Effects on growth and response function to climate. Eur. J. For. Res. 2014, 133, 323-333. [CrossRef]

68. van der Maaten, E.; Mehl, A.; Wilmking, M.; van der Maaten-Theunissen, M. Tapping the tree-ring archive for studying effects of resin extraction on the growth and climate sensitivity of Scots pine. For. Ecosyst. 2017, 4, 1-7. [CrossRef]

69. Silva, M.E.; Loureiro, C.; Pires, J. Influence of Resin Tapping on Wood Characteristics and Properties. Incredible: Innovation Networks for Cork, Resins \& Edibles. January 2020. Available online: https:/ / repository.incredibleforest.net/oppla-factsheet/20 255 (accessed on 22 December 2021). 
70. Bain, J.P. Resin Acids from Pine Tar. J. Am. Chem. Soc. 1942, 64, 871. [CrossRef]

71. Hoffmann, P. The Sucrose Method. In Conservation of Archaeological Ships and Boats-Personal Experiences; Archetype Publications: London, UK, 2013; Chapter 6.

72. Leading Sugar Producers Worldwide 2020/2021. Available online: https://www.statista.com/statistics/495973/sugarproduction-worldwide/ (accessed on 30 November 2021).

73. Tayyab, M.; Yang, Z.; Zhang, C.; Islam, W.; Lin, W.; Zhang, H. Sugarcane monoculture drives microbial community composition, activity and abundance of agricultural-related microorganisms. Environ. Sci. Pollut. Res. 2021, 28, 48080-48096. [CrossRef]

74. Beza, S.A.; Assen, M.A. Expansion of sugarcane monoculture: Associated impacts and management measures in the semi-arid East African Rift Valley, Ethiopia. Environ. Monit. Assess. 2017, 189, 111. [CrossRef] [PubMed]

75. Koch, H.-J.; Trimpler, K.; Jacobs, A.; Stockfisch, N. Crop Rotational Effects on Yield Formation in Current Sugar Beet Production-Results from a Farm Survey and Field Trials. Front. Plant Sci. 2018, 9, 231. [CrossRef] [PubMed]

76. Hofer, R. Sustainable Solutions for Modern Economies; Royal Society of Chemistry: London, UK, 2009.

77. Garthwaite, D.; Ridley, L.; Mace, A.; Parrish, G.; Barker, I.; Rainford, J.; MacArthur, R. Pesticide Usage Survey Report 284: Arable Crops in the United Kingdom 2018. Department for Environment, Food and Rural Affairs; In Report No.: 284.; 2018. Available online: https:/ / secure.fera.defra.gov.uk/pusstats/surveys/documents/arable2018.pdf (accessed on 22 December 2021).

78. Duru, M.; Therond, O.; Martin, G.; Martin-Clouaire, R.; Magne, M.-A.; Justes, E.; Journet, E.P.; Aubertot, J.N.; Savary, S.; Bergez, J.E.; et al. How to implement biodiversity-based agriculture to enhance ecosystem services: A review. Agron. Sustain. Dev. 2015, 35, 1259-1281. [CrossRef]

79. Regenerating an Ecosystem to Grow Organic Sugar: The Balbo Group. Available online: https://ellenmacarthurfoundation.org/ circular-examples/the-balbo-group (accessed on 16 November 2021).

80. Singh, R. Hybrid Membrane Systems-Applications and Case Studies. In Membrane Technology and Engineering for Water Purification, 2nd ed.; Singh, R., Ed.; Butterworth-Heinemann: Oxford, UK, 2015; Chapter 3; pp. 179-281. [CrossRef]

81. Jiang, L.; Zheng, A.; Zhao, Z.; He, F.; Li, H. Comprehensive utilization of glycerol from sugarcane bagasse pretreatment to fermentation. Bioresour. Technol. 2015, 196, 194-199. [CrossRef] [PubMed]

82. Cheng, S.; Martínez-Monteagudo, S.I. Hydrogenation of lactose for the production of lactitol. Asia-Pac. J. Chem. Eng. 2019, 14, e2275. [CrossRef]

83. Martinez-Monteagudo, S.I.; Rathnakumar, K.; Enteshari, M.; Nyuydze, C.; Osorio-Arias, J.C.; Ranaweera, H. Hundred Years of Lactitol: From Hydrogenation to Food Ingredient. In Lactose and Lactose Derivatives; Gutiérrez-Méndez, N., Ed.; IntechOpen: Rijeka, Croatia, 2020. [CrossRef]

84. Liu, D.D.; Chen, E.Y.-X. Organocatalysis in biorefining for biomass conversion and upgrading. Green Chem. 2014, 16, 964-981. [CrossRef]

85. The Nobel Prize in Chemistry 2021. Available online: https://www.nobelprize.org/prizes/chemistry/2021/press-release/ (accessed on 23 November 2021).

86. O’Neill, M.K.; Piligian, B.F.; Olson, C.D.; Woodruff, P.J.; Swarts, B.M. Tailoring Trehalose for Biomedical and Biotechnological Applications. Pure Appl. Chem. 2017, 89, 1223-1249. [CrossRef] [PubMed]

87. Schiraldi, C.; Di Lernia, I.; De Rosa, M. Trehalose production: Exploiting novel approaches. Trends Biotechnol. 2002, 20, 420-425. [CrossRef]

88. Stamm, A.J. The dimensional stability of wood. For. Prod. J. 1959, 9, 375-381.

89. United States. Patent Office. Official Gazette of the United States Patent Office. U.S. Patent Office. 1940. Available online: https:/ / play.google.com/store/books/details?id=kmedAAAAMAAJ (accessed on 22 December 2021).

90. Hoang Thi, T.T.; Pilkington, E.H.; Nguyen, D.H.; Lee, J.S.; Park, K.D.; Truong, N.P. The Importance of Poly(ethylene glycol) Alternatives for Overcoming PEG Immunogenicity in Drug Delivery and Bioconjugation. Polymers 2020, 12, 298. [CrossRef]

91. Twigg, G.H. The catalytic oxidation of ethylene. Trans. Faraday Soc. 1946, 42, 284-290. [CrossRef]

92. Herzberger, J.; Niederer, K.; Pohlit, H.; Seiwert, J.; Worm, M.; Wurm, F.R.; Frey, H. Polymerization of Ethylene Oxide, Propylene Oxide, and Other Alkylene Oxides: Synthesis, Novel Polymer Architectures, and Bioconjugation. Chem. Rev. 2016, 116, $2170-2243$. [CrossRef] [PubMed]

93. Grubbs, R.B.; Grubbs, R.H. 50th Anniversary Perspective: Living Polymerization-Emphasizing the Molecule in Macromolecules. Macromolecules 2017, 50, 6979-6997. [CrossRef]

94. Chiantore, O.; Lazzari, M. Photo-oxidative stability of paraloid acrylic protective polymers. Polymer 2001, 42, 17-27. [CrossRef]

95. Lazzari, M.; Chiantore, O. Thermal-ageing of paraloid acrylic protective polymers. Polymer 2000, 41, 6447-6455. [CrossRef]

96. Marlin, D.S.; Sarron, E.; Sigurbjörnsson, Ó. Process Advantages of Direct $\mathrm{CO}_{2}$ to Methanol Synthesis. Front. Chem. 2018, 6, 446. [CrossRef]

97. Mahboub, M.J.D.; Dubois, J.-L.; Cavani, F.; Rostamizadeh, M.; Patience, G.S. Catalysis for the synthesis of methacrylic acid and methyl methacrylate. Chem. Soc. Rev. 2018, 47, 7703-7738. [CrossRef] [PubMed]

98. Norrish, R.G.W.; Smith, R.R. Catalysed polymerization of methyl methacrylate in the liquid phase. Nature 1942, 150, 336-337. [CrossRef]

99. Merline, D.J.; Vukusic, S.; Abdala, A.A. Melamine formaldehyde: Curing studies and reaction mechanism. Polym. J. 2012, 45, 413-419. [CrossRef] 
100. Urea Production and Manufacturing Process. 4 April 2010. Available online: https://www.icis.com/explore/resources/news/20 07/11/07/9076560/urea-production-and-manufacturing-process / (accessed on 29 November 2021).

101. Kinoshita, H. Synthesis of Melamine from Urea, II. Rev. Phys. Chem. Jpn. 1954, 24, $19-27$.

102. Bazilio, C.A.; Thomas, W.J.; Ullah, U.; Hayes, K.E. The Catalytic Oxidation of Methanol. Proc. R. Soc. Lond. Ser. A Math. Phys. Sci. 1985, 399, 181-194.

103. Pham, H.Q.; Marks, M.J. Epoxy Resins. In Ullmann's Encyclopedia of Industrial Chemistry; Wiley-VCH Verlag GmbH \& Co. KGaA: Weinheim, Germany, 2005. [CrossRef]

104. Lu, Y.; Li, T.; Wang, R.; Luo, G. Synthesis of epichlorohydrin from 1,3-dichloropropanol using solid base. Chin. J. Chem. Eng. 2017, 25, 301-305. [CrossRef]

105. Stauffer, J.E. Production of Allyl Chloride. European Patent EP 0455644 B1, 5 October 1994.

106. Wang, L.; Bassiri, M.; Najafi, R.; Najafi, K.; Yang, J.; Khosrovi, B.; Hwong, W.; Barati, E.; Belisle, B.; Celeri, C.; et al. Hypochlorous acid as a potential wound care agent: Part I. Stabilized hypochlorous acid: A component of the inorganic armamentarium of innate immunity. J. Burns Wounds 2007, 6, e5.

107. Luyben, W.L. Design and Control of the Cumene Process. Ind. Eng. Chem. Res. 2010, 49, 719-734. [CrossRef]

108. Rubin, B.S. Bisphenol A: An endocrine disruptor with widespread exposure and multiple effects. J. Steroid Biochem. Mol. Biol. 2011, 127, 27-34. [CrossRef]

109. Marqueño, A.; Pérez-Albaladejo, E.; Flores, C.; Moyano, E.; Porte, C. Toxic effects of bisphenol A diglycidyl ether and derivatives in human placental cells. Environ. Pollut. 2019, 244, 513-521. [CrossRef] [PubMed]

110. Dahmen, K.; Oftring, A.; Hugo, R.; Baumann, K.; Hahn, T.; Melder, J.-P. Triethylenetetraamine Preparation Method. European Patent EP-2114861-B1, 5 September 2012.

111. Broda, M.; Majka, J.; Olek, W.; Mazela, B. Dimensional stability and hygroscopic properties of waterlogged archaeological wood treated with alkoxysilanes. Int. Biodeterior. Biodegrad. 2018, 133, 34-41. [CrossRef]

112. Broda, M.; Mazela, B.; Dutkiewicz, A. Organosilicon compounds with various active groups as consolidants for the preservation of waterlogged archaeological wood. J. Cult. Herit. 2019, 35, 123-128. [CrossRef]

113. Broda, M.; Spear, M.J.; Curling, S.F.; Ormondroyd, G.A. The Viscoelastic Behaviour of Waterlogged Archaeological Wood Treated with Methyltrimethoxysilane. Materials 2021, 14, 5150. [CrossRef]

114. Broda, M.; Dąbek, I.; Dutkiewicz, A.; Dutkiewicz, M.; Popescu, C.-M.; Mazela, B.; Maciejewski, H. Organosilicons of different molecular size and chemical structure as consolidants for waterlogged archaeological wood-A new reversible and retreatable method. Sci. Rep. 2020, 10, 1-13. [CrossRef]

115. Saka, S. Wood-inorganic composites prepared by sol-gel processing I. Wood-inorganic composites. Mokuzai Gakkaishi (J. Jpn. Wood Res. Soc.) 1992, 38, 1043-1049.

116. Saka, S.; Ueno, T. Several $\mathrm{SiO}_{2}$ wood-inorganic composites and their fire-resisting properties. Wood Sci. Technol. 1997, 31, 457-466. [CrossRef]

117. Miyafuji, H.; Saka, S. Topochemistry of $\mathrm{SiO}_{2}$ wood-inorganic composites for enhancing water-repellency. J. Soc. Mater. Sci. Jpn. 1999, 48, 270-275. [CrossRef]

118. Laine, R.M.; Furgal, J.C.; Doan, P.; Pan, D.; Popova, V.; Zhang, X. Avoiding Carbothermal Reduction: Distillation of Alkoxysilanes from Biogenic, Green, and Sustainable Sources. Angew. Chem. Int. Ed. 2016, 55, 1065-1069. [CrossRef]

119. Ethanol Explained-U.S. Energy Information Administration (EIA). Available online: https://www.eia.gov/energyexplained/ biofuels/ethanol.php (accessed on 1 December 2021).

120. Moncada, J.A.; Verstegen, J.A.; Posada, J.A.; Junginger, M.; Lukszo, Z.; Faaij, A.; Weijnen, M. Exploring policy options to spur the expansion of ethanol production and consumption in Brazil: An agent-based modeling approach. Energy Policy 2018, 123, 619-641. [CrossRef]

121. Parapouli, M.; Vasileiadis, A.; Afendra, A.-S.; Hatziloukas, E. Saccharomyces cerevisiae and its industrial applications. AIMS Microbiol. 2020, 6, 1-31. [CrossRef] [PubMed]

122. Johnstone, P.; McLeish, C. World wars and the age of oil: Exploring directionality in deep energy transitions. Energy Res. Soc. Sci. 2020, 69, 101732. [CrossRef]

123. de Souza Abud, A.K.; de Farias Silva, C.E. Bioethanol in Brazil: Status, Challenges and Perspectives to Improve the Production. In Bioethanol Production from Food Crops; Ray, R.C., Ramachandran, S., Eds.; Academic Press: Cambridge, MA, USA, 2019; Chapter 21; pp. 417-443. [CrossRef]

124. Wang, Z.X.; Zhuge, J.; Fang, H.; Prior, B.A. Glycerol production by microbial fermentation: A review. Biotechnol. Adv. 2001, 19, 201-223. [CrossRef]

125. Kandasamy, S.; Samudrala, S.P.; Bhattacharya, S. The route towards sustainable production of ethylene glycol from a renewable resource, biodiesel waste: A review. Catal. Sci. Technol. 2019, 9, 567-577. [CrossRef]

126. Li, K.; Sun, W.; Meng, W.; Yan, J.; Zhang, Y.; Guo, S.; Lü, C.; Ma, C.; Gao, C. Production of Ethylene Glycol from Glycerol Using an In Vitro Enzymatic Cascade. Catalysts 2021, 11, 214. [CrossRef]

127. Gioia, C.; Colonna, M.; Tagami, A.; Medina, L.; Sevastyanova, O.; Berglund, L.A.; Lawoko, M. Lignin-Based Epoxy Resins: Unravelling the Relationship between Structure and Material Properties. Biomacromolecules 2020, 21, 1920-1928. [CrossRef] [PubMed] 
128. Shnawa, H.A. Curing and thermal properties of tannin-based epoxy and its blends with commercial epoxy resin. Polym. Bull. 2021, 78, 1925-1940. [CrossRef]

129. Todorovic, A.; Resch-Fauster, K.; Mahendran, A.R.; Oreski, G.; Kern, W. Curing of epoxidized linseed oil: Investigation of the curing reaction with different hardener types. J. Appl. Polym. Sci. 2021, 138, 50239. [CrossRef]

130. Tran, T.-N.; Di Mauro, C.; Malburet, S.; Graillot, A.; Mija, A. Dual Cross-Linking of Epoxidized Linseed Oil with Combined Aliphatic/Aromatic Diacids Containing Dynamic S-S Bonds Generating Recyclable Thermosets. ACS Appl. Bio Mater. 2020, 3 , 7550-7561. [CrossRef]

131. Altuna, F.I.; Espósito, L.H.; Ruseckaite, R.A.; Stefani, P.M. Thermal and mechanical properties of anhydride-cured epoxy resins with different contents of biobased epoxidized soybean oil. J. Appl. Polym. Sci. 2011, 120, 789-798. [CrossRef]

132. Bayrak, A.; Kiralan, M.; Ipek, A.; Arslan, N.; Cosge, B.; Khawar, K.M. Fatty Acid Compositions of Linseed (Linum Usitatissimum, L.) Genotypes of Different Origin Cultivated in Turkey. Biotechnol. Biotechnol. Equip. 2010, 24, 1836-1842. [CrossRef]

133. Clemente, T.E.; Cahoon, E.B. Soybean oil: Genetic approaches for modification of functionality and total content. Plant Physiol. 2009, 151, 1030-1040. [CrossRef] [PubMed]

134. Chen, Q. Development of an anthraquinone process for the production of hydrogen peroxide in a trickle bed reactor-From bench scale to industrial scale. Chem. Eng. Process. Process Intensif. 2008, 47, 787-792. [CrossRef]

135. Vogel, A. Anthraquinone. In Ullmann's Encyclopedia of Industrial Chemistry; Wiley-VCH Verlag GmbH \& Co. KGaA: Weinheim, Germany, 2000. [CrossRef]

136. Igarashi, K.; Kashiwagi, K. Polyamine transport in bacteria and yeast. Biochem. J. 1999, 344, 633-642. [CrossRef] [PubMed]

137. Schneider, J.; Wendisch, V.F. Biotechnological production of polyamines by bacteria: Recent achievements and future perspectives Appl. Microbiol. Biotechnol. 2011, 91, 17-30. [CrossRef] [PubMed]

138. Qin, J.; Krivoruchko, A.; Ji, B.; Chen, Y.; Kristensen, M.; Özdemir, E.; Keasling, J.D.; Jensen, M.K.; Nielsen, J. Engineering yeast metabolism for the discovery and production of polyamines and polyamine analogues. Nat. Catal. 2021, 4, 498-509. [CrossRef]

139. Ma, W.; Chen, K.; Li, Y.; Hao, N.; Wang, X.; Ouyang, P. Advances in Cadaverine Bacterial Production and Its Applications. Proc. Est. Acad. Sci. Eng. 2017, 3, 308-317. [CrossRef]

140. Mindt, M.; Walter, T.; Kugler, P.; Wendisch, V.F. Microbial Engineering for Production of N-Functionalized Amino Acids and Amines. Biotechnol. J. 2020, 15, e1900451. [CrossRef] [PubMed]

141. Ghasemlou, M.; Daver, F.; Ivanova, E.P.; Adhikari, B. Bio-based routes to synthesize cyclic carbonates and polyamines precursors of non-isocyanate polyurethanes: A review. Eur. Polym. J. 2019, 118, 668-684. [CrossRef]

142. Herndon, J.W. 1.06-Metathesis Reactions. In Comprehensive Organometallic Chemistry II; Mingos, D.M.P., Crabtree, R.H., Eds.; Elsevier: Oxford, UK, 2007; pp. 167-195. [CrossRef]

143. Fouilloux, H.; Thomas, C.M. Production and Polymerization of Biobased Acrylates and Analogs. Macromol. Rapid Commun. 2021, 42, e2000530. [CrossRef] [PubMed]

144. Makshina, E.V.; Canadell, J.; van Krieken, J.; Peeters, E.; Dusselier, M.; Sels, B.F. Bio-acrylates production: Recent catalytic advances and perspectives of the use of lactic acid and their derivates. ChemCatChem 2019, 11, 180-201. [CrossRef]

145. Yang, J.; Xu, H.; Jiang, J.; Zhang, N.; Xie, J.; Wei, M.; Zhao, J. Production of Itaconic Acid through Microbiological Fermentation of Inexpensive Materials. J. Bioresour. Bioprod. 2019, 4, 135-142. [CrossRef]

146. Jiménez-Quero, A.; Pollet, E.; Avérous, L.; Phalip, V. Optimized Bioproduction of Itaconic and Fumaric Acids Based on Solid-State Fermentation of Lignocellulosic Biomass. Molecules 2020, 25, 1070. [CrossRef]

147. Chai, Y.; Zhao, Y.; Yan, N. Synthesis and Characterization of Biobased Melamine Formaldehyde Resins from Bark Extractives. Ind. Eng. Chem. Res. 2014, 53, 11228-11238. [CrossRef]

148. Nakata, K.; Ozaki, T.; Terashima, C. High-Yield Electrochemical Production of Formaldehyde from $\mathrm{CO}_{2}$ and Seawater. Angew. Chem. Int. Ed. 2014, 53, 871-874. [CrossRef]

149. Ghafari, R.; DoostHosseini, K.; Abdulkhani, A.; Mirshokraie, S.A. Replacing formaldehyde by furfural in urea formaldehyde resin: Effect on formaldehyde emission and physical-mechanical properties of particleboards. Eur. J. Wood Wood Prod. 2016, 74, 609-616. [CrossRef]

150. Martínez-García, A.; Ortiz, M.; Martínez, R.; Ortiz, P.; Reguera, E. The condensation of furfural with urea. Ind. Crops Prod. 2004, 19, 99-106. [CrossRef]

151. BASF Increases Prices for Impregnating Resins in Europe. Available online: https://www.basf.com/global/en/media/newsreleases /2018/07/p-18-277.html (accessed on 15 November 2021).

152. Perederic, O.A.; Mountraki, A.; Papadopoulou, E.; Woodley, J.M.; Kontogeorgis, G.M. Life Cycle Analysis of Phenol—Formaldehyde Resins Substituted with Lignin. In Computer Aided Chemical Engineering; Pierucci, S., Manenti, F., Bozzano, G.L., Manca, D., Eds.; Elsevier: Amsterdam, The Netherlands, 2020; pp. 607-612. [CrossRef]

153. Kamari, S.; Ghorbani, F. Extraction of highly pure silica from rice husk as an agricultural by-product and its application in the production of magnetic mesoporous silica MCM-41. Biomass Convers. Biorefin. 2021, 11, 3001-3009. [CrossRef]

154. Setyawan, N.; Hoerudin, H.; Wulanawati, A. Simple extraction of silica nanoparticles from rice husk using technical grade solvent: Effect of volume and concentration. IOP Conf. Ser. Earth Environ. Sci. 2019, 309, 012032. [CrossRef] 
155. Research, Markets. Global Specialty Silicas Market Report 2019-2025-Precipitated Silica Is the Driving Force for Demand Growth Globally, Which Is Projected to Record a Robust CAGR of 6\% between 2019 \& 2025. 17 December 2019. Available online: https:/ /www.globenewswire.com/en/news-release/2019/12/17/1961796/28124/en/Global-Specialty-Silicas-MarketReport-2019-2025-Precipitated-Silica-is-the-Driving-Force-for-Demand-Growth-Globally-which-is-Projected-to-Record-aRobust-CAGR-of-6-Between-2019-20.html (accessed on 26 November 2021).

156. Top Countries Based on Production of Milled Rice. Available online: https://www.statista.com/statistics/255945/top-countriesof-destination-for-us-rice-exports-2011/ (accessed on 30 November 2021).

157. Wang, B.; Yang, W.; McKittrick, J.; Meyers, M.A. Keratin: Structure, mechanical properties, occurrence in biological organisms, and efforts at bioinspiration. Prog. Mater. Sci. 2016, 76, 229-318. [CrossRef]

158. Kakkar, P.; Madhan, B.; Shanmugam, G. Extraction and characterization of keratin from bovine hoof: A potential material for biomedical applications. Springerplus 2014, 3, 596. [CrossRef] [PubMed]

159. Ashar, N.G. Chemical and Physical Properties of Sulphur Dioxide and Sulphur Trioxide. In Advances in Sulphonation Techniques: Liquid Sulphur Dioxide as a Solvent of Sulphur Trioxide; Ashar, N.G., Ed.; Springer International Publishing: Cham, Switzerland, 2016; pp. 9-19. [CrossRef]

160. Rebello, S.; Asok, A.K.; Mundayoor, S.; Jisha, M.S. Surfactants: Chemistry, Toxicity and Remediation. In Pollutant Diseases, Remediation and Recycling; Lichtfouse, E., Schwarzbauer, J., Robert, D., Eds.; Springer International Publishing: Cham, Switzerland, 2013; pp. 277-320. [CrossRef]

161. Bujak, T.; Nizioł-Łukaszewska, Z.; Wasilewski, T. Sodium Lauryl Sulfate vs. Sodium Coco Sulfate. Study of the Safety of Use Anionic Surfactants with Respect to Their Interaction with the Skin. Tenside Surfactants Deterg. 2019, 56, 126-133. [CrossRef]

162. Shah, M.S.; Tsapatsis, M.; Siepmann, J.I. Identifying Optimal Zeolitic Sorbents for Sweetening of Highly Sour Natural Gas. Angew. Chem. Int. Ed. 2016, 55, 5938-5942. [CrossRef]

163. Ohsawa, I.; Kanamori-Kataoka, M.; Tsuge, K.; Seto, Y. Determination of thiodiglycol, a mustard gas hydrolysis product by gas chromatography-mass spectrometry after tert-butyldimethylsilylation. J. Chromatogr. A 2004, 1061, 235-241. [CrossRef]

164. Cassoni, A.C.; Freixo, R.; Pintado, A.I.E.; Amorim, M.; Pereira, C.D.; Madureira, A.R.; Pintado, M.M.E. Novel Eco-Friendly Method to Extract Keratin from Hair. ACS Sustain. Chem. Eng. 2018, 6, 12268-12274. [CrossRef]

165. United States Environmental Protection Agency. Wood Products Industry. In Compilation of Air Pollutant Emissions Factors (AP-42), 5th ed.; USEPA: Washington, DC, USA, 1995. Available online: https:/ /www3.epa.gov/ttnchie1/ap42/ch10/final/c10s02.pdf. (accessed on 22 December 2021).

166. Wang, X.; Li, H.; Cao, Y.; Tang, Q. Cellulose extraction from wood chip in an ionic liquid 1-allyl-3-methylimidazolium chloride (AmimCl). Bioresour. Technol. 2011, 102, 7959-7965. [CrossRef]

167. Zhu, S.; Wu, Y.; Chen, Q.; Yu, Z.; Wang, C.; Jin, S.; Ding, Y.; Wu, G. Dissolution of cellulose with ionic liquids and its application: A mini-review. Green Chem. 2006, 8, 325-327. [CrossRef]

168. Kilpeläinen, I.; Xie, H.; King, A.; Granstrom, M.; Heikkinen, S.; Argyropoulos, D.S. Dissolution of wood in ionic liquids. J. Agric. Food Chem. 2007, 55, 9142-9148. [CrossRef]

169. Fort, D.A.; Remsing, R.C.; Swatloski, R.P.; Moyna, P.; Moyna, G.; Rogers, R.D. Can ionic liquids dissolve wood? Processing and analysis of lignocellulosic materials with 1-n-butyl-3-methylimidazolium chloride. Green Chem. 2007, 9, 63-69. [CrossRef]

170. Sun, N.; Rahman, M.; Qin, Y.; Maxim, M.L.; Rodríguez, H.; Rogers, R.D. Complete dissolution and partial delignification of wood in the ionic liquid 1-ethyl-3-methylimidazolium acetate. Green Chem. 2009, 11, 646-655. [CrossRef]

171. Zavrel, M.; Bross, D.; Funke, M.; Büchs, J.; Spiess, A.C. High-throughput screening for ionic liquids dissolving (ligno-)cellulose. Bioresour. Technol. 2009, 100, 2580-2587. [CrossRef] [PubMed]

172. Zhang, H.; Wu, J.; Zhang, J.; He, J. 1-Allyl-3-methylimidazolium Chloride Room Temperature Ionic Liquid: A New and Powerful Nonderivatizing Solvent for Cellulose. Macromolecules 2005, 38, 8272-8277. [CrossRef]

173. Abushammala, H.; Mao, J. A Review on the Partial and Complete Dissolution and Fractionation of Wood and Lignocelluloses Using Imidazolium Ionic Liquids. Polymers 2020, 12, 195. [CrossRef] [PubMed]

174. Berglund, L.; Anugwom, I.; Hedenström, M.; Aitomäki, Y.; Mikkola, J.-P.; Oksman, K. Switchable ionic liquids enable efficient nanofibrillation of wood pulp. Cellulose 2017, 24, 3265-3279. [CrossRef]

175. Zhong, C. Industrial-Scale Production and Applications of Bacterial Cellulose. Front. Bioeng. Biotechnol. 2020, 8, 605374. [CrossRef] [PubMed]

176. Chen, H.-H.; Chen, L.-C.; Huang, H.-C.; Lin, S.-B. In situ modification of bacterial cellulose nanostructure by adding CMC during the growth of Gluconacetobacter xylinus. Cellulose 2011, 18, 1573-1583. [CrossRef]

177. Moniri, M.; Boroumand Moghaddam, A.; Azizi, S.; Abdul Rahim, R.; Bin Ariff, A.; Zuhainis Saad, W.; Navaderi, M.; Mohamad, R. Production and Status of Bacterial Cellulose in Biomedical Engineering. Nanomaterials 2017, 7, 257. [CrossRef]

178. Portela, R.; Leal, C.R.; Almeida, P.L.; Sobral, R.G. Bacterial cellulose: A versatile biopolymer for wound dressing applications. Microb. Biotechnol. 2019, 12, 586-610. [CrossRef] [PubMed]

179. Czaja, W.K.; Young, D.J.; Kawecki, M.; Brown, R.M., Jr. The future prospects of microbial cellulose in biomedical applications. Biomacromolecules 2007, 8, 1-12. [CrossRef]

180. Keshk, S.M.A.S. Bacterial Cellulose Production and Its Industrial Applications. J. Bioprocess Biotech. 2014, 4, 100150. [CrossRef]

181. Ullah, M.W.; Ul-Islam, M.; Khan, S.; Kim, Y.; Park, J.K. Innovative production of bio-cellulose using a cell-free system derived from a single cell line. Carbohydr. Polym. 2015, 132, 286-294. [CrossRef] [PubMed] 
182. Kim, Y.; Ullah, M.W.; Ul-Islam, M.; Khan, S.; Jang, J.H.; Park, J.K. Self-assembly of bio-cellulose nanofibrils through intermediate phase in a cell-free enzyme system. Biochem. Eng. J. 2019, 142, 135-144. [CrossRef]

183. Antonelli, F.; Galotta, G.; Sidoti, G.; Zikeli, F.; Nisi, R.; Davidde Petriaggi, B.; Romagnoli, M. Cellulose and Lignin Nano-Scale Consolidants for Waterlogged Archaeological Wood. Front. Chem. 2020, 8, 32. [CrossRef] [PubMed]

184. Younes, I.; Rinaudo, M. Chitin and chitosan preparation from marine sources. Structure, properties and applications. Mar. Drugs 2015, 13, 1133-1174. [CrossRef]

185. Ospina Álvarez, S.P.; Ramírez Cadavid, D.A.; Escobar Sierra, D.M.; Ossa Orozco, C.P.; Rojas Vahos, D.F.; Zapata Ocampo, P.; Atehortúa, L. Comparison of Extraction Methods of Chitin from Ganoderma lucidum Mushroom Obtained in Submerged Culture. BioMed Res. Int. 2014, 2014, 169071. [CrossRef]

186. El Knidri, H.; Belaabed, R.; Addaou, A.; Laajeb, A.; Lahsini, A. Extraction, chemical modification and characterization of chitin and chitosan. Int. J. Biol. Macromol. 2018, 120, 1181-1189. [CrossRef] [PubMed]

187. Rakshit, S.; Mondal, S.; Pal, K.; Jana, A.; Soren, J.P.; Barman, P.; Mondal, K.C.; Halder, S.K. Extraction of chitin from Litopenaeus vannamei shell and its subsequent characterization: An approach of waste valorization through microbial bioprocessing. Bioprocess Biosyst. Eng. 2021, 44, 1943-1956. [CrossRef]

188. Hajji, S.; Ghorbel-Bellaaj, O.; Younes, I.; Jellouli, K.; Nasri, M. Chitin extraction from crab shells by Bacillus bacteria. Biological activities of fermented crab supernatants. Int. J. Biol. Macromol. 2015, 79, 167-173. [CrossRef] [PubMed]

189. Tan, Y.N.; Lee, P.P.; Chen, W.N. Microbial extraction of chitin from seafood waste using sugars derived from fruit waste-stream AMB Express 2020, 10, 17. [CrossRef]

190. Harkin, C.; Brück, W.M.; Lynch, C. Isolation \& identification of bacteria for the treatment of brown crab (Cancer pagurus) waste to produce chitinous material. J. Appl. Microbiol. 2015, 118, 954-965. [CrossRef] [PubMed]

191. Aytekin, O.; Elibol, M. Cocultivation of Lactococcus lactis and Teredinobacter turnirae for biological chitin extraction from prawn waste. Bioprocess Biosyst. Eng. 2010, 33, 393-399. [CrossRef]

192. Liu, P.; Liu, S.; Guo, N.; Mao, X.; Lin, H.; Xue, C.; Wei, D. Cofermentation of Bacillus licheniformis and Gluconobacter oxydans for chitin extraction from shrimp waste. Biochem. Eng. J. 2014, 91, 10-15. [CrossRef]

193. Bajpai, P. Wood-Based Products and Chemicals. In Biermann's Handbook of Pulp and Paper, 3rd ed.; Bajpai, P., Ed.; Elsevier: Amsterdam, The Netherlands, 2018; Chapter 8; pp. 233-247. [CrossRef]

194. Lobato-Peralta, D.R.; Duque-Brito, E.; Vidales, H.I.V.; Longoria, A.; Sebastian, P.J.; Cuentas-Gallegos, A.K.; Arancibia-Bulnes, C.A.; Okoye, P.U. A review on trends in lignin extraction and valorization of lignocellulosic biomass for energy applications. $J$. Clean. Prod. 2021, 293, 126123. [CrossRef]

195. Laurichesse, S.; Avérous, L. Chemical modification of lignins: Towards biobased polymers. Prog. Polym. Sci. 2014, 39, 1266-1290. [CrossRef]

196. Vishtal, A.G.; Kraslawski, A. Challenges in industrial applications of technical lignins. BioResources 2011, 6, 3547-3568. [CrossRef]

197. Florian, T.D.M.; Villani, N.; Aguedo, M.; Jacquet, N.; Thomas, H.G.; Gerin, P.; Magali, D.; Richel, A. Chemical composition analysis and structural features of banana rachis lignin extracted by two organosolv methods. Ind. Crops Prod. 2019, 132, 269-274. [CrossRef]

198. Watkins, D.; Nuruddin Hosur, M.; Tcherbi-Narteh, A.; Jeelani, S. Extraction and characterization of lignin from different biomass resources. J. Mater. Res. Technol. 2015, 4, 26-32. [CrossRef]

199. Michelin, M.; Liebentritt, S.; Vicente, A.A.; Teixeira, J.A. Lignin from an integrated process consisting of liquid hot water and ethanol organosolv: Physicochemical and antioxidant properties. Int. J. Biol. Macromol. 2018, 120, 159-169. [CrossRef] [PubMed]

200. Zikeli, F.; Vinciguerra, V.; Taddei, A.R.; D'Annibale, A.; Romagnoli, M.; Mugnozza, G.S. Isolation and characterization of lignin from beech wood and chestnut sawdust for the preparation of lignin nanoparticles (LNPs) from wood industry side-streams. Holzforschung 2018, 72, 961-972. [CrossRef]

201. Ding, X.; Richter, D.L.; Matuana, L.M.; Heiden, P.A. Efficient one-pot synthesis and loading of self-assembled amphiphilic chitosan nanoparticles for low-leaching wood preservation. Carbohydr. Polym. 2011, 86, 58-64. [CrossRef]

202. Kashyap, P.L.; Xiang, X.; Heiden, P. Chitosan nanoparticle based delivery systems for sustainable agriculture. Int. J. Biol. Macromol. 2015, 77, 36-51. [CrossRef]

203. Ela, R.C.A.; Tajiri, M.; Newberry, N.K.; Heiden, P.A.; Ong, R.G. Double-Shell Lignin Nanocapsules Are a Stable Vehicle for Fungicide Encapsulation and Release. ACS Sustain. Chem. Eng. 2020, 8, 18730-18731.

204. Machado, T.O.; Beckers, S.J.; Fischer, J.; Müller, B.; Sayer, C.; de Araújo, P.H.; Landfester, K.; Wurm, F.R. Bio-Based Lignin Nanocarriers Loaded with Fungicides as a Versatile Platform for Drug Delivery in Plants. Biomacromolecules 2020, 21, 2755-2763. [CrossRef] [PubMed]

205. Yiamsawas, D.; Beckers, S.J.; Lu, H.; Landfester, K.; Wurm, F.R. Morphology-Controlled Synthesis of Lignin Nanocarriers for Drug Delivery and Carbon Materials. ACS Biomater. Sci. Eng. 2017, 3, 2375-2383. [CrossRef]

206. Chen, N.; Dempere, L.A.; Tong, Z. Synthesis of pH-Responsive Lignin-Based Nanocapsules for Controlled Release of Hydrophobic Molecules. ACS Sustain. Chem. Eng. 2016, 4, 5204-5211. [CrossRef]

207. Baglioni, P.; Chelazzi, D.; Giorgi, R. Deacidification of Paper, Canvas and Wood. In Nanotechnologies in the Conservation of Cultural Heritage: A Compendium of Materials and Techniques; Baglioni, P., Chelazzi, D., Giorgi, R., Eds.; Springer: Dordrecht, The Netherlands, 2015; pp. 117-144. [CrossRef] 
208. Haw, T.T.; Hart, F.; Rashidi, A.; Pasbakhsh, P. Sustainable cementitious composites reinforced with metakaolin and halloysite nanotubes for construction and building applications. Appl. Clay Sci. 2020, 188, 105533. [CrossRef]

209. Cavallaro, G.; Lazzara, G.; Milioto, S.; Parisi, F.; Sparacino, V. Thermal and dynamic mechanical properties of beeswax-halloysite nanocomposites for consolidating waterlogged archaeological woods. Polym. Degrad. Stab. 2015, 120, 220-225. [CrossRef]

210. Cavallaro, G.; Lazzara, G.; Milioto, S.; Parisi, F.; Ruisi, F. Nanocomposites based on esterified colophony and halloysite clay nanotubes as consolidants for waterlogged archaeological woods. Cellulose 2017, 24, 3367-3376. [CrossRef]

211. Cavallaro, G.; Lazzara, G.; Parisi, F.; Riela, S. Nanoclays for Conservation and Nanomaterials. In Nanotechnologies and Nanomaterials for Diagnostic, Conservation and Restoration of Cultural Heritage; Lazzara, G., Fakhrullin, R., Eds.; Elsevier: Amsterdam, The Netherlands, 2019; pp. 149-170. [CrossRef]

212. Infurna, G.; Cavallaro, G.; Lazzara, G.; Milioto, S.; Dintcheva, N.T. Bionanocomposite Films Containing Halloysite Nanotubes and Natural Antioxidants with Enhanced Performance and Durability as Promising Materials for Cultural Heritage Protection Polymers 2020, 12, 1973. [CrossRef] [PubMed]

213. Lisuzzo, L.; Hueckel, T.; Cavallaro, G.; Sacanna, S.; Lazzara, G. Pickering Emulsions Based on Wax and Halloysite Nanotubes: An Ecofriendly Protocol for the Treatment of Archeological Woods. ACS Appl. Mater. Interfaces 2021, 13, 1651-1661. [CrossRef]

214. Bettina, G.F.; Giambra, B.; Cavallaro, G.; Lazzara, G. Restoration of a XVII Century's predella reliquary: From Physico-Chemical Characterization to the Conservation Process. Forests 2021, 12, 345. [CrossRef]

215. Cavallaro, G.; Milioto, S.; Lazzara, G. Halloysite Nanotubes: Interfacial Properties and Applications in Cultural Heritage. Langmuir 2020, 36, 3677-3689. [CrossRef] [PubMed]

216. Lisuzzo, L.; Cavallaro, G.; Milioto, S.; Lazzara, G. Halloysite nanotubes filled with salicylic acid and sodium diclofenac: Effects of vacuum pumping on loading and release properties. J. Nanostruct. Chem. 2021, 11, 663-673. [CrossRef]

217. Lisuzzo, L.; Cavallaro, G.; Milioto, S.; Lazzara, G. Halloysite Nanotubes Coated by Chitosan for the Controlled Release of Khellin. Polymers 2020, 12, 1766. [CrossRef]

218. Dzamukova, M.R.; Naumenko, E.A.; Lvov, Y.M.; Fakhrullin, R.F. Enzyme-activated intracellular drug delivery with tubule clay nanoformulation. Sci. Rep. 2015, 5, 1-11. [CrossRef]

219. Vikulina, A.; Voronin, D.; Fakhrullin, R.; Vinokurov, V.; Volodkin, D. Naturally derived nano- and micro-drug delivery vehicles: Halloysite, vaterite and nanocellulose. New J. Chem. 2020, 44, 5638-5655. [CrossRef]

220. Sun, L.; Mills, D.K. Halloysite nanotube-based drug delivery system for treating osteosarcoma. Conf. Proc. IEEE Eng. Med. Biol. Soc. 2014, 2014, 2920-2923. [CrossRef]

221. Walsh, Z.; Janeček, E.R.; Hodgkinson, J.T.; Sedlmair, J.; Koutsioubas, A.; Spring, D.R.; Welch, M.; Hirschmugl, C.J.; Toprakcioglu, C.; Nitschke, J.R.; et al. Multifunctional supramolecular polymer networks as next-generation consolidants for archaeological wood conservation. Proc. Natl. Acad. Sci. USA 2014, 111, 17743-17748. [CrossRef]

222. Castro-López, C.; Contreras-Esquivel, J.C.; Martinez-Avila, G.C.; Rojas, R.; Boone-Villa, D.; Aguilar, C.N.; Ventura-Sobrevilla, J.M Guar gum as a promising hydrocolloid: Properties and industry overview. In Applied Chemistry and Chemical Engineering; Apple Academic Press: Cambridge, MA, USA, 2017; pp. 183-205. [CrossRef]

223. Colombini, M.P.; Lucejko, J.J.; Modugno, F.; Orlandi, M.; Tolppa, E.-L.; Zoia, L. A multi-analytical study of degradation of lignin in archaeological waterlogged wood. Talanta 2009, 80, 61-70. [CrossRef] [PubMed]

224. McHale, E.; Braovac, S.; Steindal, C.C.; Gillis, R.B. Synthesis and characterisation of lignin-like oligomers as a bio-inspired consolidant for waterlogged archaeological wood. Pure Appl. 2016, 88, 969-977. [CrossRef]

225. Khalil, A.A.; Rahman, U.; Khan, M.R.; Sahar, A.; Mehmood, T.; Khan, M. Essential oil eugenol: Sources, extraction techniques and nutraceutical perspectives. RSC Adv. 2017, 7, 32669-32681. [CrossRef]

226. McHale, E.; Steindal, C.C.; Kutzke, H.; Benneche, T.; Harding, S.E. In situ polymerisation of isoeugenol as a green consolidation method for waterlogged archaeological wood. Sci. Rep. 2017, 7, 46481. [CrossRef] [PubMed]

227. Cutajar, M.; Andriulo, F.; Thomsett, M.R.; Moore, J.C.; Couturaud, B.; Howdle, S.M.; Stockman, R.A.; Harding, S.E. Terpene polyacrylate TPA5 shows favorable molecular hydrodynamic properties as a potential bioinspired archaeological wood consolidant. Sci. Rep. 2021, 11, 7343. [CrossRef]

228. Adamová, T.; Hradecký, J.; Pánek, M. Volatile Organic Compounds (VOCs) from Wood and Wood-Based Panels: Methods for Evaluation, Potential Health Risks, and Mitigation. Polymers 2020, 12, 2289. [CrossRef] [PubMed]

229. ReSolve Project Developed Bio-Based Alternatives to Replace Toxic Solvents Used in the Chemical Industry. Available online: https: / / www.bbi.europa.eu/resolve-project-developed-bio-based-alternatives-replace-toxic-solvents-used-chemicalindustry (accessed on 30 November 2021). 